\title{
Design and Immunological Evaluation of a Hybrid Peptide as a Potent TLR2 Agonist by Structure-Based Virtual Screening
}

\author{
Lulu Zhang', Xubiao Wei 1,2,3, Rijun Zhang ${ }^{1 *}$, Paul E. Mozdziak ${ }^{3}$, Dayong Si', \\ Baseer Ahmad ${ }^{1}$, Qiang Cheng ${ }^{1}$ and Yucui Tong ${ }^{1}$
}

'State Key Laboratory of Animal Nutrition, College of Animal Science and Technology, China Agricultural University, Beijing, China, ${ }^{2}$ School of Pharmaceutical Sciences, Tsinghua University, Beijing, China, ${ }^{3}$ Prestage Department of Poultry Science, College of Agriculture and Life Sciences, North Carolina State University, Raleigh, NC, United States

\section{OPEN ACCESS}

Edited by:

Mario Antonio Bianchet,

Johns Hopkins University,

United States

Reviewed by:

Simone Brogi,

University of Pisa, Italy

Andrei I. Khlebnikov,

Tomsk Polytechnic University, Russia

*Correspondence:

Rijun Zhang

rjzhang@cau.edu.cn

Specialty section:

This article was submitted to

Molecular Medicine,

a section of the journal

Frontiers in Cell and Developmental

Biology

Received: 22 October 2020

Accepted: 15 January 2021

Published: 11 February 2021

Citation:

Zhang L, Wei X, Zhang $R$,

Mozdziak PE, Si D, Ahmad B, Cheng $Q$ and Tong $Y$ (2021) Design and Immunological Evaluation of a Hybrid Peptide as a Potent TLR2 Agonist by Structure-Based Virtual

Screening.

Front. Cell Dev. Biol. 9:620370. doi: 10.3389/fcell.2021.620370
Immunity is a versatile defensive response that is involved in protecting against disease by identifying and destroying self and non-self harmful substances. As a state of temporary or permanent immune dysfunction, immunosuppression can make an organism more susceptible to infection, organ injury, and cancer due to damage to the immune system. It has taken a long time to develop new immunomodulatory agents to prevent and treat immunosuppressive diseases. In recent years, Toll-like receptor 2 (TLR2) agonists have been reported to have profound effects on the immune system, and they are regarded as potent immunomodulatory candidates. TP5 and LL-37, the potent immunomodulatory agents, have been reported to produce a robust innate immune response by binding to TLR2. However, their development has been weakened by several concerns, such as potential cytotoxicity, weak physiological stability and poor immunomodulatory activity. To overcome these challenges, hybridization has been proposed. Therefore, six hybrid peptides (LTPa, LTPb, LTPC, TPLa, TPLb, and TPLC) were designed by combining the full-length TP5 with a characteristic fragment of LL-37 that included LL-37 (13-36), LL-37 (17-29), and LL-37 (13-31). LTPa, the most potent TLR2 agonist, was simply and effectively screened by molecular docking and in vitro experiments. Furthermore, the immunomodulatory effects of LTPa were confirmed by a CTX-immunosuppressed murine model, which demonstrated that LTPa successfully inhibit immunosuppression, increased immune organ indices, enhanced DC maturation, regulated $T$ lymphocyte subsets, and increased cytokine and Ig contents. Our study also revealed that the immunomodulatory effects of LTPa are associated with binding to TLR2, forming TLR2 clusters, and activating the NF- $\kappa$ B signaling pathway.

Keywords: immunoregulatory activity, TLR2, molecule docking, cyclophosphamide, NF- $\kappa$ B signaling

Abbreviations: TLRs, Toll-like receptors; DCs, Dendritic cells; TNF- $\alpha$, tumor necrosis factor-alpha; IL-6, interleukin-6; TP5, thymopentin; CTX, cyclophosphamide; LTPa, LL-37-TP5a; LTPb, LL-37-TP5b; LTPc, LL-37-TP5c; TPLa, TP5-LL-37a; TPLb, TP5-LL-37b; TPLc, TP5-LL-37c; HPLC, high-performance liquid chromatography; MS, mass spectrometry; DMEM, Dulbecco's modified Eagle’s medium; FBS, fetal bovine serum; CCK-8, Cell Counting Kit-8; PerCP, Peridinin-ChlorophyllProtein Complex; APC, Allophycocyanin; FITC, fluorescein isothiocyanate; PBMCs, eripheral blood mononuclear cells; MHC-II, MHC class II; MD, molecular dynamics; NPT, constant number, pressure, and temperature; NVT, constant number, volume, and temperature; MM-PBSA, Poisson-Boltzmann accessible surface area; NF- $\kappa$ b, nuclear factor-kappa B; CE TAL, Chromogenic End-point Tachypleus Amebocyte Lysate; MD, molecular dynamics; SPR, Surface plasmon resonance; Ka, kinetic rate constant; $K \mathrm{~d}$, the dissociation rate constant; $K \mathrm{D}$, equilibrium dissociation constant. 


\section{INTRODUCTION}

Immunity is a versatile defensive response that is involved in protecting against disease by identifying and destroying self and non-self harmful substances or microbiological toxins (Hooper et al., 2012). As a state of temporary or permanent immune dysfunction, immunosuppression can make an organism more susceptible to infection, organ injury, and cancer due to damage to the immune system (Goldszmid et al., 2014). Therefore, it is necessary to develop a new immunomodulatory agent to prevent and treat immunosuppressive diseases.

Toll-like receptors (TLRs) are thought of as pathogen recognition receptors for exogenous pathogens and have also been shown to play prominent roles in host defense and in regulating immune responses (Akira et al., 2006). TLR2 is an important signal transduction molecule that is expressed on dendritic cells (DCs), macrophages and activated CD4 + T cells (Komai-Koma et al., 2004). TLR2 activates the secretion of proinflammatory cytokines such as tumor necrosis factor alpha (TNF- $\alpha$ ), interleukin-6 (IL-6), and IL-1 $\beta$ from monocytes, macrophages and dendritic cells, thereby triggering the activation of the immune response (Oliveira-Nascimento et al., 2012). Therefore, TLR2 agonists, such as $\beta$-glucan (Quayle et al., 2015) and $\mathrm{Pam}_{3} \mathrm{CSK}_{4}$ (Su et al., 2019), are promising candidates as vaccine adjuvants and pharmaceuticals that support immunotherapies.

Thymopentin (TP5), the Arg32-Tyr36 fragment derived from thymopoietin, was able to restore the thymic atrophy induced by immunosuppressants (Goldstein et al., 1979; Singh et al., 1998). TP5 was found to exert its immunoregulatory activity by binding TLR2 (Li et al., 2013). Additionally, TP5 plays an important role in T-lymphocyte maturation and differentiation, thereby regulating immunity (Mendling and Koldovsky, 1996; London et al., 2011). Overall, TP5 is used in the treatment of immunodeficiencies, malignancies, and infections due to its immunoregulatory activity and low cytotoxicity.

LL-37, a human cationic host-defense peptide, has been reported to have a robust innate immune response by binding to TLR2 (Mansour et al., 2014; Zhang et al., 2016; Agier et al., 2018). In addition, LL-37 stimulates the production of various immunoregulatory mediators, proinflammatory cytokines, and chemokines (Scott et al., 2002; Tjabringa et al., 2003; Bowdish et al., 2004). Therefore, LL-37 could prevent or attenuate immunosuppression.

TP5 plays a vitally important role in the process of immune enhancement. However, the development of TP5 has been weakened by its short half-life, which decreases its efficacy and bioavailability (Gonser et al., 2004; Hu et al., 2016). LL37 has a long half-life, but its clinical development has been hampered by its cytotoxicity (Anders et al., 2018). As a simple and effective strategy that could combine the advantages of different native peptides (Li et al., 2014; Wei et al., 2018), hybridization has been proposed to obtain a peptide with more potent immunoregulatory activity but minimal cytotoxicity. As previously reported, LL-37 (13-36) (Mookherjee et al., 2006; Molhoek et al., 2009), LL-37 (17-29) (Li et al., 2006; Tan et al., 2017), and LL-37 (13-31) (Wei et al., 2018) exhibit robust immunoregulatory activity. Therefore, six hybrid peptides were designed by combining the full-length TP5 (Gonser et al., 2004; $\mathrm{Hu}$ et al., 2016) with a characteristic fragment of LL-37 that included LL-37 (13-36) (Mookherjee et al., 2006; Molhoek et al., 2009), LL-37 (17-29) (Li et al., 2006; Tan et al., 2017), and LL-37 (13-31) (Wei et al., 2018). The hybrid peptides were screened by molecular docking and in vitro experiments based on their immunoregulatory activity and cytotoxicity. The immunoregulatory mechanisms of the best hybrid peptide were further analyzed by exploring the molecular basis of its immunoregulatory effects using a cyclophosphamide (CTX)immunosuppressed murine model. The objective of the study was to develop a TLR agonist using a novel screeing strategy. The aim was to develop a model system that could lead to a potential therapeutic to improve the immune system in immunocompromised individuals.

\section{MATERIALS AND METHODS}

\section{Hybrid Peptide Design}

The hybrid peptides LL-37-TP5a (LTPa, IGKEFKRIVQRIK DFLRNLVPRTERKDVY), LL-37-TP5b (LTPb, FKRIVQRIKD FLRRKDVY), LL-37-TP5c (LTPc, IGKEFKRIVQRIKDFL RNLRKDVY), TP5-LL-37a (TPLa, RKDVYIGKEFKRIVQRIKD FLRNLVPRTE), TP5-LL-37b (TPLb, RKDVYFKRIVQRIK DFLR), and TP5-LL-37c (TPLc, RKDVYIGKEFKRIVQRIKDFL RNL) were designed by combining TP5 (RKDVY) with three active centers of LL-37, including LL-37a (IGKEFKRIVQRIKDFLRNLVPRTE), LL-37b (FKRIVQRI KDFLR), and LL-37c (IGKEFKRIV QRIKDFLRNL). The key physicochemical parameters of the peptides were calculated online using ExPASy Proteomics Server ${ }^{1}$. The initial 3D structures of all these hybrid peptides were generated through MOE suit and I-TASSER online server I-TASSER ${ }^{2}$.

\section{Circular Dichroism Spectra}

The Circular dichroism (CD) spectroscopy of the hybrid peptides was performed at $25^{\circ} \mathrm{C}$ using a Jasco- 810 spectropolarimeter (Jasco, Tokyo, Japan). The peptides were dissolved in $10 \mathrm{mM}$ PBS (pH 7.4, mimicking an aqueous environment) and 50\% $(\mathrm{v} / \mathrm{v})$ TFE (mimicking the hydrophobic environment of the cell membrane) at a concentration of $0.1 \mathrm{mg} / \mathrm{mL}$. The measurements were recorded at wavelengths ranging from 190 to $250 \mathrm{~nm}$.

\section{Molecular Docking}

The initial structures of the hybrid peptides were then subjected to molecular docking. The published TLR2 structure (PDB code: 1 FYW) was used as a receptor structure for molecule docking. All the default optimization parameters were used for the iterated search in Vina. ZDOCK3.0.2 was used to produce the initial TLR2-hybrid peptide complex. A total of 3,600 decoy structures of each TLR2-hybrid peptide complex were predicted through the rigid-binding option in ZDOCK. The decoy with

\footnotetext{
${ }^{1}$ http://www.expasy.org/tools/protparam.html

${ }^{2}$ http://zhanglab.ccmb.med.umich.edu/I-TASSER/
} 
the lowest energy was selected for the flexible docking study. One hundred docking runs of each molecule were performed by flexpepdock ${ }^{3}$. The most plausible docking conformation with the lowest interface energy was chosen for hybrid peptide scanning.

\section{Peptide Synthesis}

All of the peptides used in this study were synthesized and purified by KangLong Biochemistry (Jiangsu, China). The purity of the peptide was determined to be greater than $95 \%$ by highperformance liquid chromatography (HPLC). The peptides were identified through mass spectrometry (MS) and dissolved in endotoxin-free water (Supplementary Figure S1).

\section{Cell Culture}

The murine macrophage cell line RAW264.7 (Shanghai Cell Bank, Shanghai, China) was cultured in Dulbecco's modified Eagle's medium (DMEM; HyClone Logan, UT, United States) and incubated in a humidified atmosphere of $5 \% \mathrm{CO}_{2}$ at $37^{\circ} \mathrm{C}$. DMEM was supplemented with $10 \%(\mathrm{v} / \mathrm{v})$ fetal bovine serum (FBS; Gibco, Foster, CA, United States) and 1\% (v/v) penicillin/streptomycin (HyClone).

\section{Cell Viability Assay}

The cytotoxicity of the peptides against RAW264.7 cells was measured using a Cell Counting Kit-8 (CCK-8) Assay Kit (Dojindo) as previously described (Liu Z.H. et al., 2013). Briefly, cells were seeded in 96-well plates at a final density of $2.0 \times 10^{4}$ cells/well overnight. The cells were incubated with different concentrations of each peptide $(0-80 \mu \mathrm{g} / \mathrm{mL})$ for $24 \mathrm{~h}$ and then further incubated with CCK-8 solution for $4 \mathrm{~h}$ at $37^{\circ} \mathrm{C}$ in darkness. The OD value was then measured using a microplate reader (TECAN, Switzer) at $450 \mathrm{~nm}$. Cell viability was calculated using the equation:

$$
\text { Cell viability }(\%)=\frac{\text { OD } 450(\text { sample })}{\text { OD } 450(\text { control })} \times 100 \%
$$

Where OD450 (sample) is the OD value at $450 \mathrm{~nm}$ by peptidetreated cells and OD450 (control) is the OD value at $450 \mathrm{~nm}$ by the cells without peptide treatment.

\section{In vitro Immunomodulatory Activity of Peptides}

RAW264.7 cells were seeded at a density of $1.0 \times 10^{6}$ cell $/ \mathrm{mL}$ and treated with $(10 \mu \mathrm{g} / \mathrm{mL})$ or without peptides in each well of a 6-well plate for $12 \mathrm{~h}$ at $37^{\circ} \mathrm{C}$ in a humidified incubator with $5 \% \mathrm{CO}_{2}$. After treatment, TNF- $\alpha$, IL- 6 and IL- $1 \beta$ secretion in the cell supernatants was assessed using ELISA kits according to the manufacturer's instructions.

\section{Experimental Animals}

BALB/c mice (female, 6-8 weeks; Charles River, Beijing, China) used in this study were maintained in a specific-pathogenfree facility $\left(55 \pm 10 \%\right.$ humidity and $\left.22 \pm 1{ }^{\circ} \mathrm{C}\right)$ during the experiments. These experiments were conducted with approval

${ }^{3} \mathrm{http} / / /$ flexpepdock.furmanlab.cs.huji.ac.il/ from the Institutional Animal Care and Use Committee of China Agricultural University (certificate of the Beijing Laboratory Animal employee, ID: 18086).

After a 7-day adaptation period, the mice were randomly divided into five groups ( $n=12$ in each group): (1) control group: physiological saline was injected intraperitoneally once daily; (2) cyclophosphamide (CTX) group: CTX (80 mg/kg mouse weight; Sigma-Aldrich, St. Louis, MO, United States) was injected intraperitoneally once daily for the first 3 days. From days 4 to 10 (7 days), physiological saline was injected intraperitoneally into mice once daily; and (3) CTX + peptide (LL-37, TP5, or LTPa) groups: CTX (80 mg/kg mouse weight) was injected intraperitoneally once daily for three consecutive days. From days 4 to 10 , peptide (10 $\mathrm{mg} / \mathrm{kg}$ mouse weight) was injected intraperitoneally into mice once daily. Twenty-four hours after the last drug administration, all the mice were weighed and then euthanized, and their tissues and blood were collected for further study. The body weight index was calculated according to the formula:

$$
\text { Index }(\%)=\frac{\text { final body weight }- \text { inital body weight }}{\text { initial body weight }} \times 100
$$

The thymus and spleen indices were measured by the following formula:

$$
\text { Index }(\mathrm{mg} / \mathrm{g})=\frac{\text { weight of thymus or spleen }}{\text { body weight }}
$$

\section{Peripheral Blood T Lymphocyte Subpopulations Analyzed by Flow Cytometry}

Erythrocytes were aseptically obtained from the different groups of mouse peripheral blood and lysed with RBC lysis buffer. The remaining cells were washed with PBS and resuspended in PBS. The cells were combined with peridininchlorophyll-protein complex (PerCP)-conjugated anti-mouse $\mathrm{CD} 3+$, allophycocyanin (APC)-conjugated anti-mouse CD4 +, and fluorescein isothiocyanate (FITC)-conjugated anti-mouse $\mathrm{CD} 8+$ (BD Pharmingen, United States) for $30 \mathrm{~min}$ at $4^{\circ} \mathrm{C}$. The T lymphocyte subpopulations were analyzed by flow cytometry.

\section{Phenotypic Analysis by Flow Cytometry}

Mouse peripheral blood mononuclear cells (PBMCs) were obtained from the different groups of mice through Ficoll density gradient centrifugation. The cells were resuspended in PBS with 5\% FBS and incubated with $10 \%(\mathrm{v} / \mathrm{v})$ normal goat serum for $15 \mathrm{~min}$ at $4^{\circ} \mathrm{C}$. The cells were combined with FITCconjugated antibodies specific for MHC class II (MHC-II; BD Pharmingen, United States). The surface expression of MHC-II was determined by flow cytometry.

\section{Serum Cytokine and Immunoglobulin (Ig) Measurements by ELISA}

Serum was collected from blood and then assayed by ELISA kits according to the protocol supplied by the manufacturer (eBioscience, San Diego, United States) to determine the secretion of IgG, IgA, IgM, TNF- $\alpha$, IL-6, and IL- $1 \beta$. 


\section{Blocking Experiments}

For TLR2 blocking experiments, RAW264.7 cells were cultured in 24-well plates overnight at $37^{\circ} \mathrm{C}$. The mouse IgG2a isotype control antibody or anti-mouse TLR2 (C9A12; InvivoGen, San Diego, CA, United States) was added to the cell cultures $1 \mathrm{~h}$ before being treated with LTPa for $24 \mathrm{~h}$ at $37^{\circ} \mathrm{C}$. Then, the levels of TNF- $\alpha$, IL- 6 , and IL- $1 \beta$ in the culture supernatant were analyzed.

\section{Molecular Dynamics Simulation}

To assess the binding affinity of LTPa with TLR2, the docking pose of LTPa-TLR2 was assessed by RosettaDock (version 3.5), and the missing hydrogen atoms in this system were added by Maestro at pH 7.0 (Sastry et al., 2013). The pose with the lowest binding energy was selected for further study.

The best binding poses of LTP with TLR2 were subjected to molecular dynamics (MD) simulation under AMBER14 (Duan et al., 2003; Wang et al., 2005). The GAFF and FF14SB force fields were used for peptides and proteins, respectively. The LTP-TLR2 complex was solvated in a cubic box of TIP3P water with a minimum distance of $10 \AA$ and then neutralized by adding an appropriate number of $\mathrm{Na}^{+}$and $\mathrm{Cl}^{-}$atoms (Jorgensen et al., 1983). The first 1,000 steps were used to minimize the system by the conjugate gradient algorithm. The system was then heated gradually at a constant number, pressure, and temperature (NPT) for 100 ps (Parrinello and Rahman, 1981). After that, a $60 \mathrm{~ns}$ MD simulation was performed under a constant number, volume, and temperature (NVT) ensemble. The molecular mechanics Poisson-Boltzmann accessible surface area (MM-PBSA) binding free energy was calculated for the LTP-TLR2 complex (Massova and Kollman, 2000). The particlemesh Ewald method was employed to address the long-range electrostatic interactions.

\section{Surface Plasmon Resonance}

Surface plasmon resonance (SPR) experiments were carried out using a Biacore X100 instrument (GE Healthcare, Pittsburgh, PA, United States) by standard amine coupling. TLR2 (R\&D Systems, Minneapolis, MN, United States) was amine-coupled to a Biacore CM5 sensor chip (Bio-Rad). The peptide was diluted to varying concentrations $(0,1.25,2.5,5$, and $10 \mathrm{mM})$ in running buffer (PBS containing 0.05\% Tween 20) and run sequentially over immobilized TLR2. Binding curves were processed for the initial injection alignment and baseline, and a reference-subtracted sensorgram was globally fitted to the curves to describe a homogeneous 1:1 model. Data analysis was conducted using ProteOn manager software (version 2.0). Data from the protein surfaces were grouped together to fit the association kinetic rate constant $(\mathrm{Ka})$ and the dissociation rate constant $(K \mathrm{~d})$. The equilibrium dissociation constant $(K \mathrm{D})$ for the peptide-TLR2 interaction was calculated as follows:

$$
K D=\frac{K d}{K a}
$$

\section{Confocal Laser-Scanning Microscopy}

RAW264.7 cells were treated with or without $10 \mu \mathrm{g} / \mathrm{mL}$ LTPa for $1 \mathrm{~h}$ at $37^{\circ} \mathrm{C}$. The cells were then incubated ( $30 \mathrm{~min}$, on ice) with anti-mouse monoclonal antibody TLR2 or isotype control (IgG) (eBioscience) before washing with PBS. Then, the cells were stained with a FITC-conjugated anti-mouse IgG antibody for $30 \mathrm{~min}$ on ice (Jackson Laboratories). After washing with PBS and fixing with paraformaldehyde, the cell nuclei were stained with DAPI (1:500 dilution in PBS) (Sigma-Aldrich). The cells were then imaged with the Leica TCS SP5 confocal system (Leica Microsystems Ltd.). LAS AF software was used to process the images and quantify the fluorescence. In addition, to generate a fluorescence histogram profile, a line was drawn along the cell surface. Fluorescence intensities higher than 40 arbitrary units (isotype control staining) were considered clusters of TLR2 molecules.

\section{Western Blot Analysis}

Whole proteins were extracted from the serum using a wholeprotein extraction kit (Nanjing KeyGEN Biotech, Nanjing, China). The protein concentrations were determined with the BCA Assay (KeyGEN Biotech, Nanjing, China) according to the manufacturer's instructions. Equivalent amounts of protein were separated by SDS-PAGE and blotted onto polyvinylidene fluoride membranes (Bio-Rad). After blocking with 5\% nonfat dried milk in TBS $/ 0.05 \%$ Tween-20 for $2 \mathrm{~h}$ at room temperature, the membranes were immunoblotted with primary specific antibodies (anti-TLR2, anti-TRAF6, anti-TAK1, antiIкB- $\alpha$, anti-p-IкB- $\alpha$, anti-NF- $\kappa$ B (p65), anti-p-NF- $\kappa$ B (p-p65), and anti- $\beta$-actin (Abcam, United Kingdom) at $4^{\circ} \mathrm{C}$ overnight. After washing with TBST, the membranes were incubated with horseradish peroxidase (HRP)-conjugated secondary antibody (HuaAn, Hangzhou, China) for $1 \mathrm{~h}$ at room temperature. Proteins were visualized using a ChemiDoc ${ }^{\mathrm{TM}}$ MP Imaging System (Bio-Rad). Quantitative data were evaluated by means of Image software.

\section{Statistics}

All experiments were carried out with at least three biological replicates. The data are presented as the means \pm SD. Statistical comparisons were performed by Student's $t$ test and one-way ANOVA using GraphPad Prism 7 software.

\section{RESULTS}

\section{Screening of Immunomodulatory Peptides}

Table 1 shows the sequences of the hybrid peptides and their parental peptides. To scan a hybrid peptide with desired immunomodulatory activity, the binding ability of the hybrid peptides to TLR2 was determined by molecular docking. LTPa had lower binding energy than the other hybrid peptides (Figure 1), and its total score was lower than -100.

The immunomodulatory activities of these hybrid peptides were then evaluated by in vitro experiments, which suggested 
TABLE 1 | The sequence of the peptides.

\begin{tabular}{lc}
\hline Peptides & Sequence \\
\hline LL-37 & LLGDFFRKSKEKIGKEFKRIVQRIKDFLRNLVPRTES \\
TP5 & RKDVT \\
LTPa & IGKEFKRIVQRIKDFLRNLVPRTERKDVT \\
LTPb & FKRIVQRIKDFLRRKDVT \\
LTPC & IGKEFKRIVQRIKDFLRNLRKDVT \\
TPLa & RKDVTIGKEFKRIVQRIKDFLRNLVPRTE \\
TPLb & RKDVT FKRIVQRIKDFLR \\
TPLC & RKDVTIGKEFKRIVQRIKDFLRNL \\
\hline
\end{tabular}

that the hybrid peptides LTPa, LTPb and LTPc and their parental peptides caused remarkable increases in TNF$\alpha$ (Figure 2A), IL-6 (Figure 2B), and IL-1 $\beta$ (Figure 2C) production. However, TPLa, TPLb, and TPLc exhibited no significant increases in these cytokines. In addition, LTPa significantly increased the secretion of TNF- $\alpha$, IL-6, and IL-1 $\beta$ in comparison with the other peptides tested. Collectively, these data suggest that LTPa, the most active peptide, was worthwhile focus for further immunomodulatory experiments.

\section{Cytotoxicity on RAW264.7 Macrophage Cells}

The cytotoxic activity of LTPa and its parental peptides (LL37 and TP5) toward RAW264.7 macrophages was evaluated by CCK-8 assay. As shown in Figure 3, LTPa exhibited no significant cytotoxicity even at $80 \mu \mathrm{g} / \mathrm{mL}$. In addition, the results showed that the cytotoxicity of LTPa was lower than that of its parental peptides (LL-37 and TP5).

\section{Bodyweight and Immune Organ Indices}

As expected, there was a significant decrease in the bodyweight of the CTX-treated group compared with the control group (Figure 4A). However, after 7 days of treatment, LL-37, TP5, and LTPa improved bodyweight rapidly. In addition, bodyweight in the LTPa-treated group was significantly higher than that in the parental peptide (LL-37 and TP5)-treated groups (Figure 4A). In addition, the results showed that compared with the control group, the spleen (Figure 4B) and

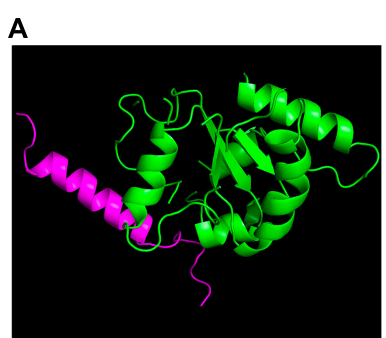

(a)

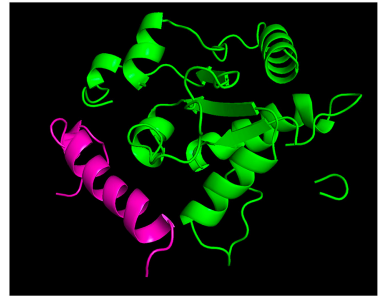

(d)

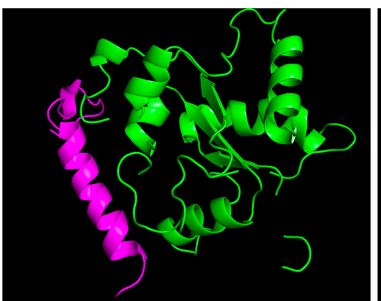

(b)

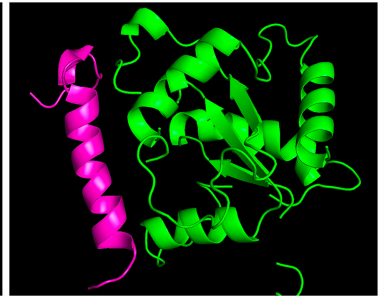

(e)

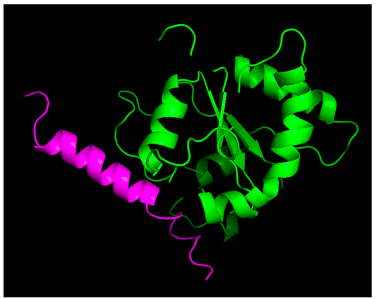

(c)

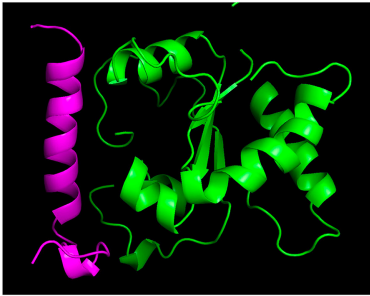

(f)

B

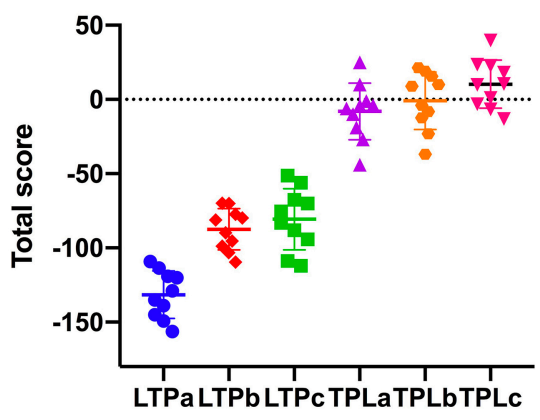

FIGURE 1 | The binding of ability of the hybrid peptides to TLR2. (A) The overall structure of the peptide-TLR2 complex. The green ribbons represent TLR2, and the red ribbons represent the hybrid peptide. (B) Energy plot. Ten out of 100 decoy structures from the hybrid peptide-TLR2 docking study by flexpepdock. Data are means \pm SD. 

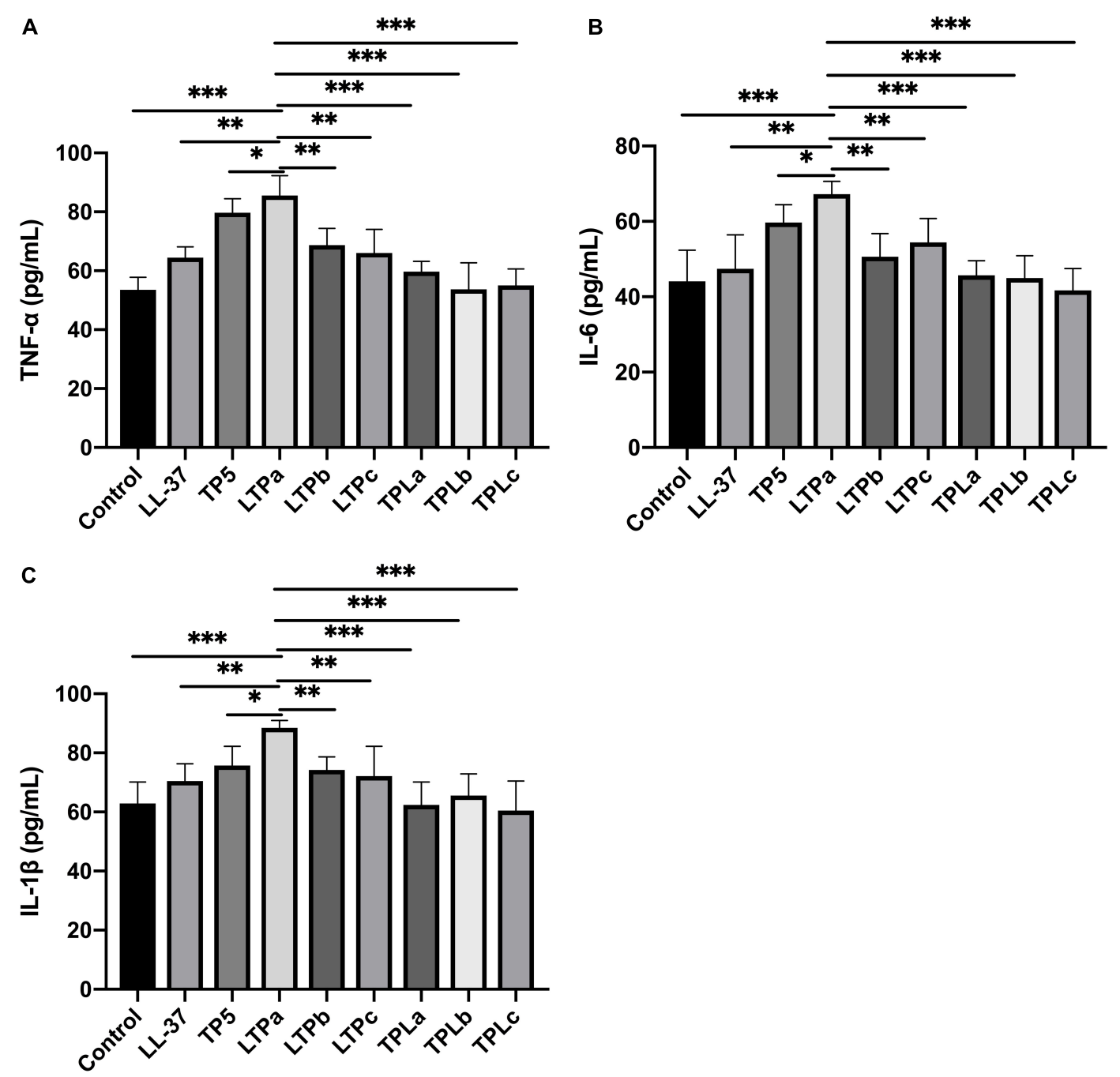

FIGURE 2 | The in vitro immunomodulatory activity of the hybrid peptides. The mouse macrophages (RAW264.7) were treated with $10 \mu \mathrm{g} / \mathrm{mL}$ hybrid peptides for $12 \mathrm{~h}$. After treatment, TNF- $\alpha \mathbf{( A )}, \mathrm{IL}-6$ (B) and IL-1 $\beta$ (C) secretion in the cell supernatants was assessed using ELISA kits. The mean values \pm SD from three independent experiments were used to express the data. ${ }^{*} p \leq 0.05,{ }^{* *} p \leq 0.01$, and ${ }^{* * *} p \leq 0.001$.

thymus (Figure 4C) indices were significantly decreased in the CTX-treated group. Peptide treatment remarkably improved the spleen (Figure 4B) and thymus (Figure 4C) indices, and the immune organ indices in the LTPa-treated group were significantly higher than those in the LL-37-treated and TP5treated groups.

\section{Effect of LTPa on T Lymphocyte Subpopulations}

Compared with the control group, CTX remarkably reduced the proportions of $\mathrm{CD} 4+$ and $\mathrm{CD} 8+\mathrm{T}$ lymphocytes (Figures 5A,B). Treatment with peptides significantly increased the proportions of $\mathrm{CD} 4+$ and $\mathrm{CD} 8+\mathrm{T}$ lymphocytes. In addition, the increasing level in the LTPa-treated group was significantly higher than that in the LL-37-treated group and similar to that in the TP5-treated group.
To evaluate the anti-inflammatory effect of CTP and its parental peptides, CATH2 and TP5, RAW264.7 cells were used as a model. The results showed that LPS caused significant elevation of the pro-inflammatory cytokines TNF- $\alpha$ (Figure 2A), IL-6 (Figure 2B), and IL-1 $\beta$ (Figure 2C) compared with untreated cells. As shown in Figures $\mathbf{2 A - C}$, all the peptides attenuated the TNF- $\alpha$, IL- $1 \beta$, and IL- 6 secretion levels. Furthermore, compared with its parental peptides, CTP exerted enhanced inhibitory activity against LPS-induced inflammation.

\section{Effect of LTPa on DC Maturation}

To investigate the effect of LTPa on serum DC maturation, the expression levels of DC phenotype factor (MHC-II) were determined by flow cytometry. The results showed that the expression of MHC-II was significantly decreased in the CTXtreated group but increased by LTPa treatment (Figure 6). In addition, the expression of MHC-II in the LTPa-treated group 


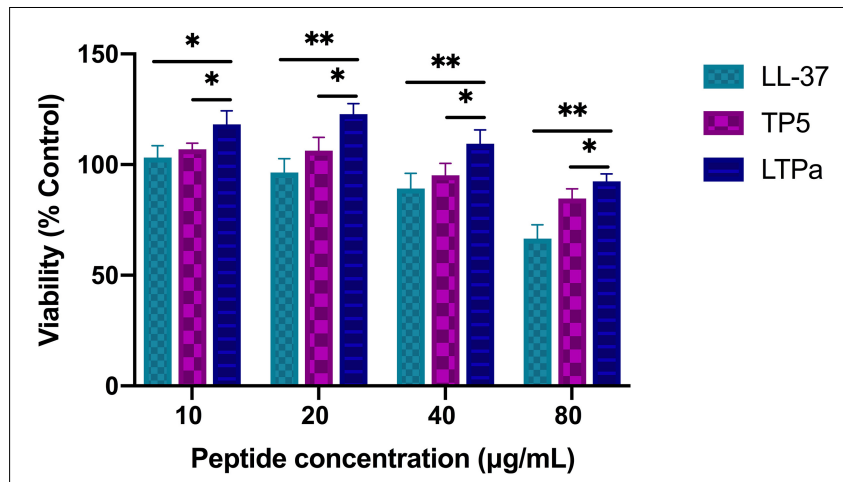

FIGURE 3 | Cell proliferation rates of RAW264.7 cells. RAW264.7 macrophages were treated with various doses of peptides $(10,20,40$, and $80 \mu \mathrm{g} / \mathrm{mL}$ ) at $37^{\circ} \mathrm{C}$ and $5 \% \mathrm{CO}_{2}$ for $24 \mathrm{~h}$. Cell proliferation rates were measured by microplate at $450 \mathrm{~nm}$ using CCK8 assay. The mean values \pm SD from 12 independent experiments were used to express the data. ${ }^{*} p \leq 0.05$, and ${ }^{* *} p \leq 0.01$.

was significantly higher than that in the LL-37-treated and TP5treated groups (Figure 6).

\section{Effects of LTPa on Serum Cytokines and Immunoglobulin}

To investigate the immunomodulatory activity of LTPa in CTX-treated mice, serum TNF- $\alpha$, IL-6, and IL-1 $\beta$ levels were evaluated by ELISA. As shown in Figures 7A-C, serum TNF- $\alpha$ (Figure 7A), IL-6 (Figure 7B), and IL-1 $\beta$ (Figure 7C) levels were significantly decreased due to treatment with CTX. However, peptide administration caused a significant increase in the serum TNF- $\alpha$ (Figure 7A), IL-6 (Figure 7B), and IL-1 $\beta$ (Figure 7C) levels compared with the CTX-treated group. In addition, in the LTPa-treated group, TNF- $\alpha$, IL- 6 , and IL- $1 \beta$ levels were higher than those in the TP5- or LL-37-treated groups.

The levels of serum IgA (Figure 7D), IgG (Figure 7E), and IgM (Figure 7F) in the CTX-treated group were significantly reduced compared with those in the control group. All of the peptides tested reversed the declines in serum IgA (Figure 7D), IgG (Figure 7E), and IgM (Figure 7F), and LTPa-treated mice had significantly higher total serum IgA, IgG, and IgM levels than mice in the TP5- or LL-37-treated groups.

\section{LTPa Interacts Directly With TLR2 to Activate the TLR2-NF- $\kappa$ B Signaling \\ Pathway}

A total of 300 snapshots were observed from the last stable $40 \mathrm{~ns}$ of the MD simulation for the LTPa-TLR2 complex to understand how LTPa may interact with TLR2. The predicted binding free energy was used to reflect the binding affinity of LTPa. Table 2 represents the predicted binding energy of LTPa to be $-798.5 \mathrm{~kJ} / \mathrm{mol}$. In addition, the interaction between LTPa and TLR2 primarily involved hydrogen bonds and salt-bridges (Figure 8C and Table 3).

To explore the mechanism underlying the capacity of LTPa to interact with TLR2, we first examined cell surface TLR2

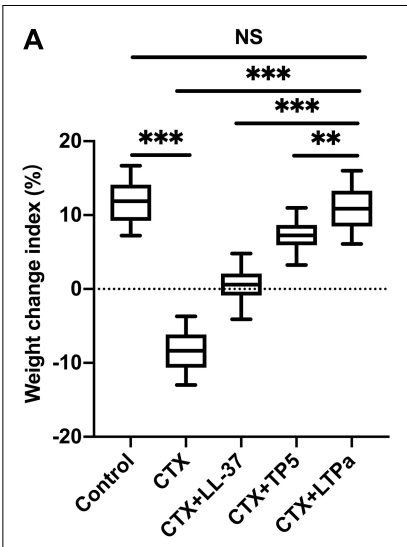

B
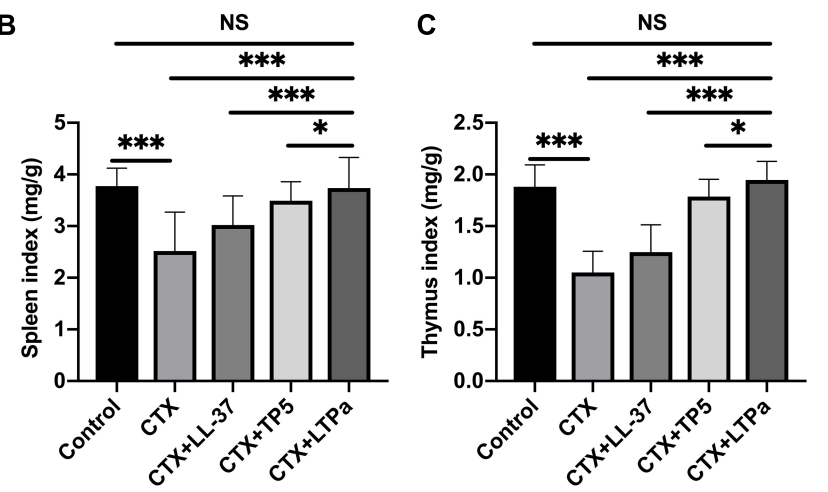

FIGURE 4 | The effects of LTPa on body weight (A), spleen index (B), and thymus index (C). After a 7-day adaptation period, the mice were randomly divided into five groups ( $n=12$ in each group): control group: physiological saline was injected intraperitoneally once daily; cyclophosphamide (CTX) group: CTX ( $80 \mathrm{mg} / \mathrm{kg}$ mouse weight) was injected intraperitoneally once daily for the first 3 days. From days 4 to 10 (7 days), physiological saline was injected intraperitoneally into mice once daily; CTX + peptide (LL-37, TP5, or LTPa) group: CTX (80 mg/kg mouse weight) was injected intraperitoneally once daily for three consecutive days. From days 4 to 10, peptide (10 mg/kg mouse weight) was injected intraperitoneally into mice once daily. The body weight was recorded before and after the experiment. The spleen weights and thymus weights of the mice were examined after 10 days of treatment. The mean values $\pm S D$ of 12 biological replicates were used to express the data. NS, $p>0.05 ;{ }^{*} p \leq 0.05 ;{ }^{* *} p \leq 0.01$; and ${ }^{* * *} p \leq 0.001$.

cluster formation because TLR clustering is believed to be critical to signaling (Pfeiffer et al., 2001; Triantafilou et al., 2002). In the absence of LTPa, TLR2 showed an even distribution on the cell surface with very few clusters per micrometer (Figure 8D). However, LTPa significantly increased the number of major TLR2 clusters per micrometer on the cell surface (Figure 8D).

Next, the TLR2-NF- $\kappa$ B signaling pathway was investigated to determine the mechanism underlying the immunomodulatory activity of LTPa. CTX significantly decreased the expression levels of TLR2, MyD88, and TRAF6 and the phosphorylation of IKK$\beta, \mathrm{I} \kappa \mathrm{B}-\alpha$, and NF- $\kappa \mathrm{B}$, while cells that were treated with LTPa exhibited dampened levels of TLR2, MyD88, and TRAF6 and phosphorylation of IKK- $\beta, \mathrm{I} \kappa \mathrm{B}-\alpha$, and NF- $\kappa \mathrm{B}$ (Figure 9). These results suggest that LTPa exerts its immunomodulatory activity by activating the TLR2-NF- $\kappa$ B pathway. 


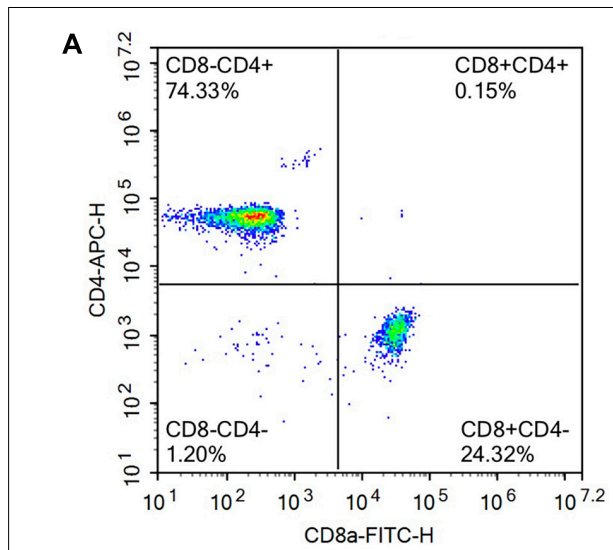

(a)

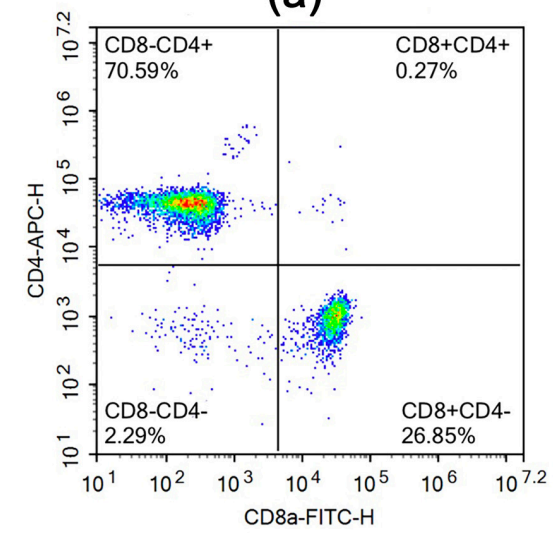

(d)

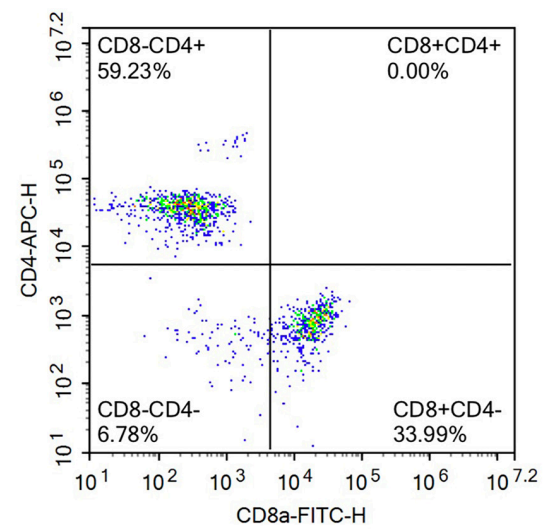

(b)

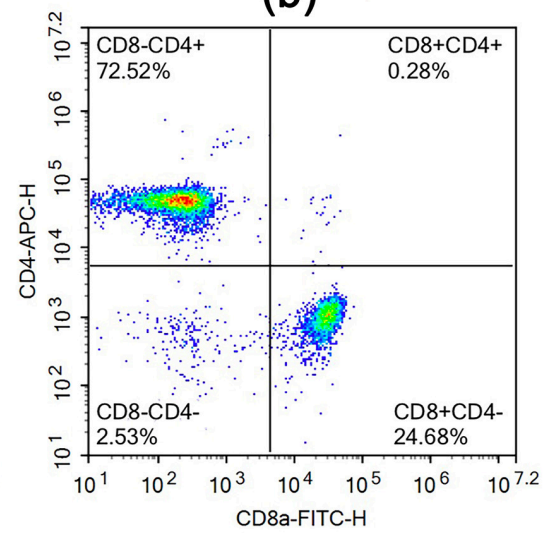

(e)

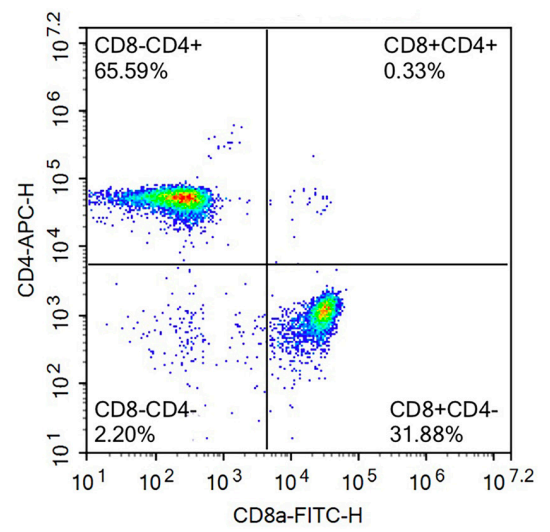

(c)

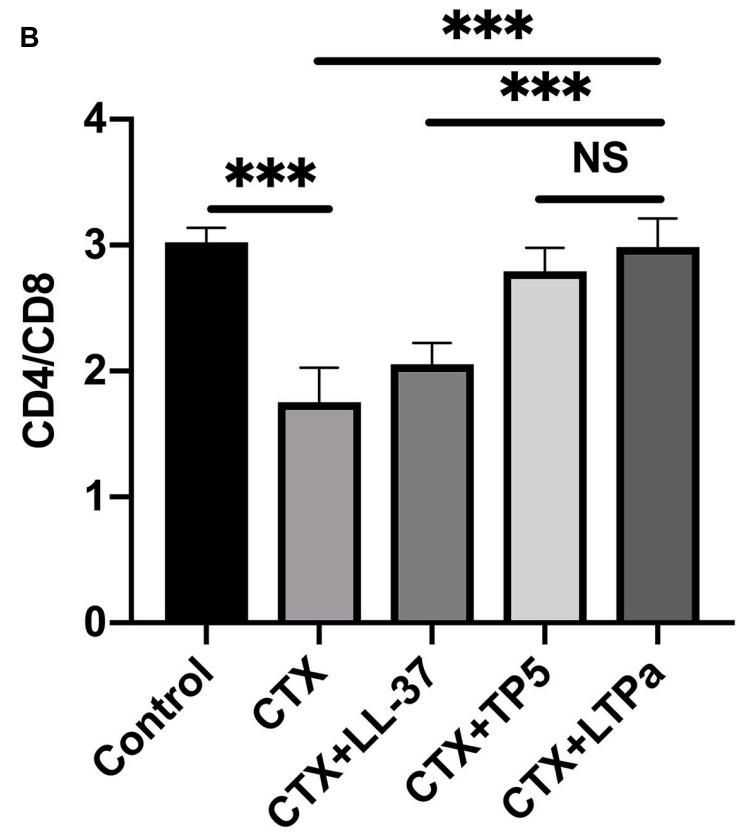

FIGURE 5 | Effects of LTPa on T lymphocyte subpopulations. Erythrocytes were aseptically obtained from the different groups of mouse peripheral blood and lysed with RBC lysis buffer. The cells were combined with PerCP-conjugated anti-mouse CD3 +, APC-conjugated anti-mouse CD4 +, and FITC-conjugated anti-mouse $\mathrm{CD} 8+$ for $30 \mathrm{~min}$ at $4^{\circ} \mathrm{C}$. The T lymphocyte subpopulations were analyzed by flow cytometry. (A) The percentage of different T cell subsets was analyzed by flow cytometry. (A,a) Control, (A,b) cyclophosphamide (CTX), (A,c) LL-37 + CTX, (A,d) TP5 + CTX, (A,e) LTP + CTX. Bivariate plots are shown as representative, independent assessments that were quantified and plotted as the CD4+:CD8+ ratio in part (B). The mean values \pm SD of three biological replicates were used to express the data. NS: $p>0.05$, and ${ }^{* * *} p \leq 0.001$. 


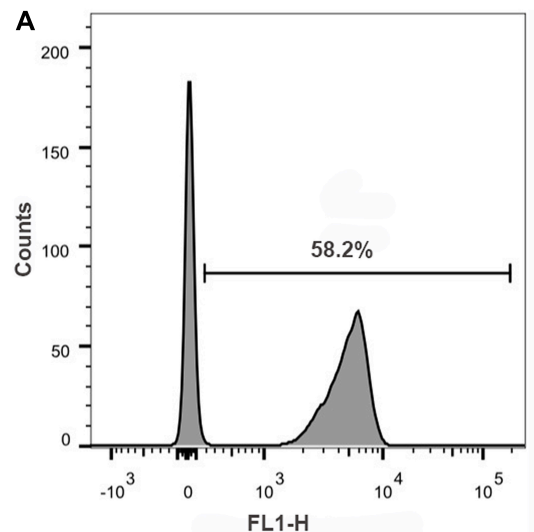

(a)

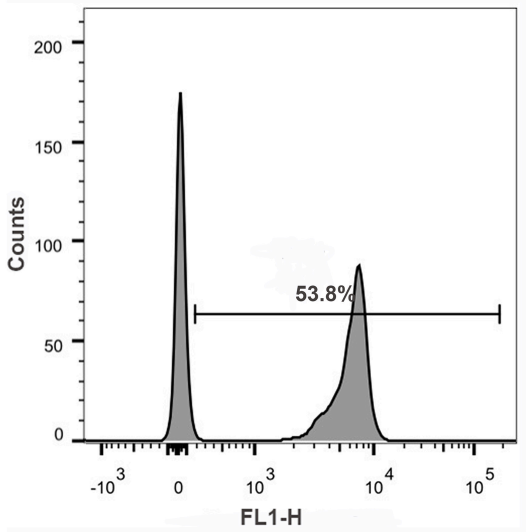

(d)

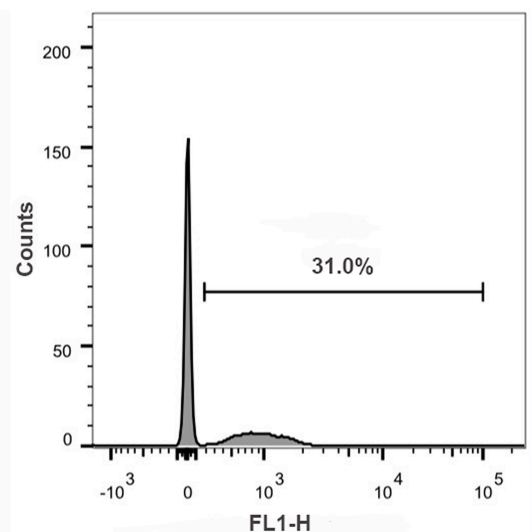

(b)

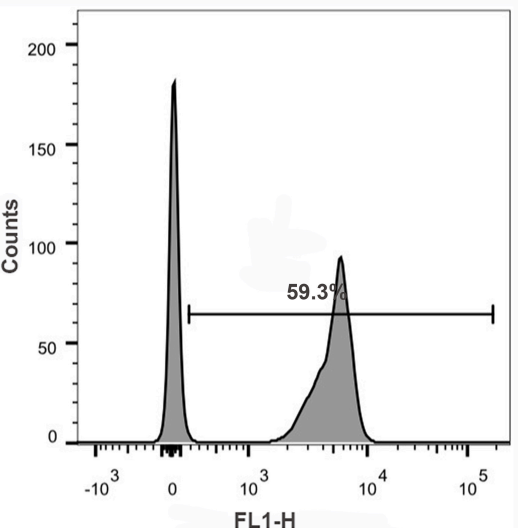

(e)

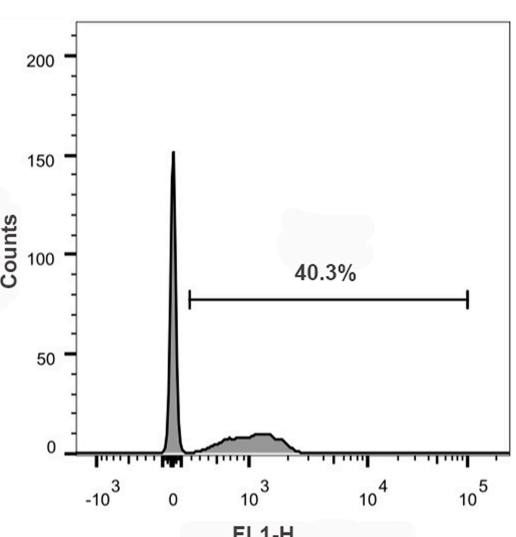

(c)

B

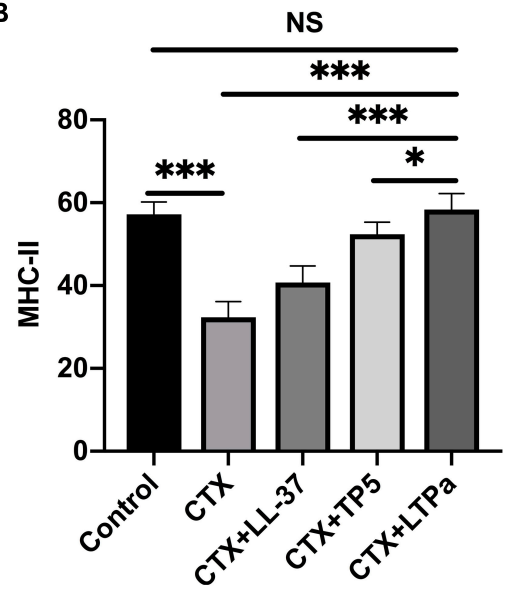

FIGURE 6 | Effects of LTPa on DC maturation. Mouse PBMCs were obtained from the different groups of mice. The cells were combined with FITC-conjugated antibodies specific for $\mathrm{MHC}$ class II. The surface expression of MHC-II was determined by flow cytometry. (A) The percentage of different T cell subsets was analyzed by flow cytometry. (A,a) Control, (A,b) cyclophosphamide (CTX), (A,c) LL-37 + CTX, (A,d) TP5 + CTX, (A,e) LTPa + CTX. Bivariate plots are shown as representative, independent assessments that were quantified and plotted as the CD4+:CD8+ ratio in part (B). The mean values \pm SD of three biological replicates were used to express the data. NS: $p>0.05,{ }^{*} p \leq 0.05$, and ${ }^{* * *} p \leq 0.001$.

\section{DISCUSSION}

As a state of temporary or permanent immune dysfunction, immunosuppression can make an organism more susceptible to infection, organ injury, and cancer (Goldszmid et al., 2014). Development of new immunomodulatory agents to prevent and treat immunosuppressive diseases has taken a long time. Meanwhile, in recent years, immunomodulatory peptides have 

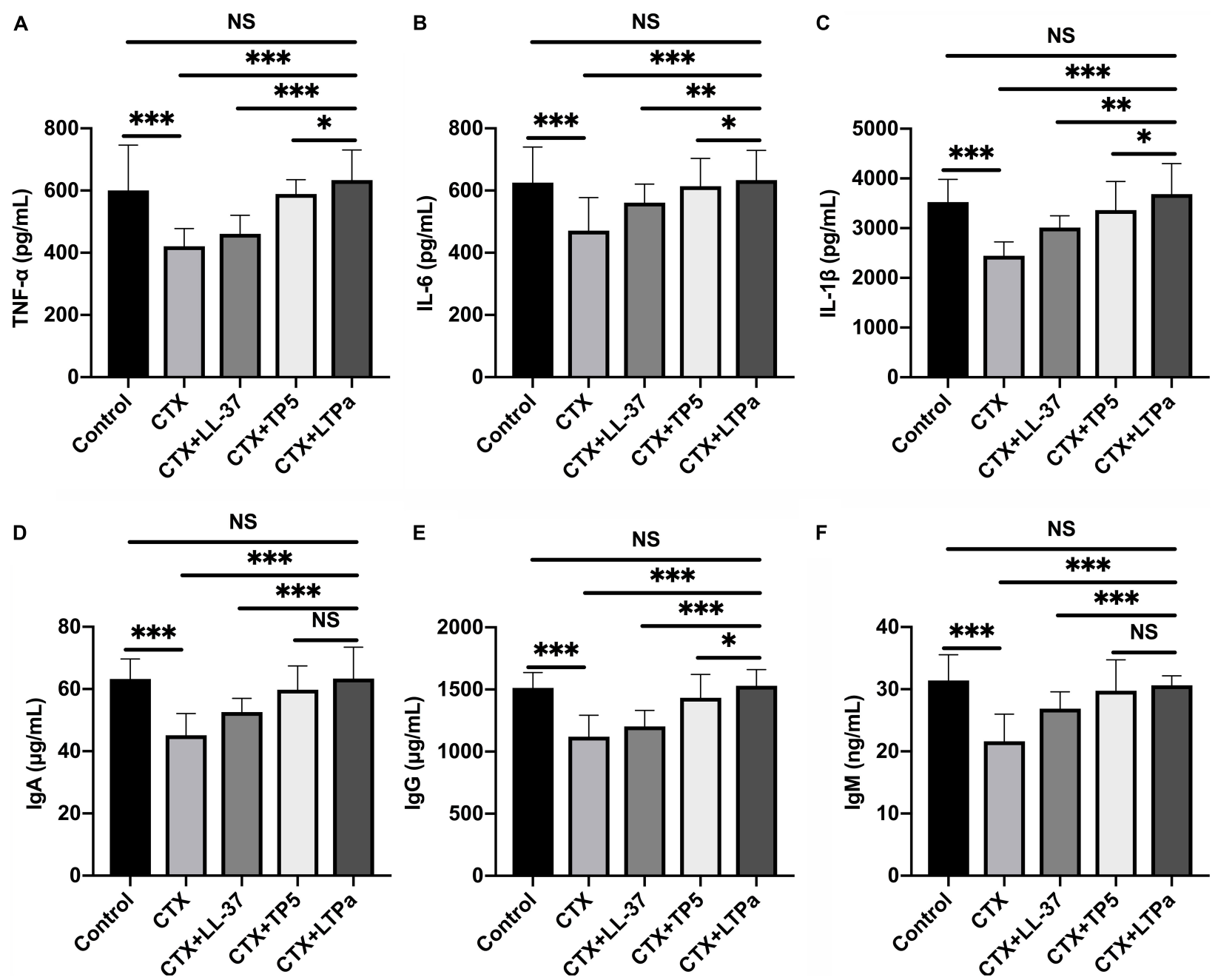

FIGURE 7 | Effects of LTPa on serum cytokines and immunoglobulin. Levels of TNF- $\alpha$ (A), IL-6 (B), IL-1 $\beta$ (C), IgA (D), IgG (E), and IgM (F) were detected in serum from different groups of mice through ELISA. The mean values $\pm \mathrm{SD}$ of three biological replicates were used to express the data. NS, $p>0.05,{ }^{*} p \leq 0.05$,

${ }^{* *} p \leq 0.01$, and ${ }^{* * *} p \leq 0.001$.

been reported to have profound effects on the immune system, thereby being regarded as potent immunomodulatory candidates with a wide range of applications (Nijnik and Hancock, 2009; Chen et al., 2010; Li et al., 2012; Romani et al., 2017). Among them, TP5 and LL-37 have displayed enormous potential in the treatment of various immunosuppressive diseases (Nijnik and Hancock, 2009; Chen et al., 2010). However, their development has been weakened by several concerns, such as potential cytotoxicity (Anders et al., 2018), weak physiological stability and poor immunomodulatory activity (Gonser et al., 2004;

TABLE 2 | Key interaction parameters between LTPa and TLR2.

\begin{tabular}{lcccc}
\hline Interaction Pair & $\begin{array}{c}\text { Number of } \\
\text { Hydrogen } \\
\text { bonds }\end{array}$ & $\begin{array}{c}\text { Number of } \\
\text { Salt-bridges }\end{array}$ & $\begin{array}{c}\text { Interaction } \\
\text { Surface }\left(\AA^{2}\right)\end{array}$ & $\begin{array}{c}\text { Binding free } \\
\text { energy } \\
\text { (kj/mol) }\end{array}$ \\
\hline TLR2 . LTPa & 11 & 7 & 293 & -798.5
\end{tabular}

Hu et al., 2016). To overcome all these challenges, hybridization has been proposed (Liu Y.F. et al., 2013; Ma et al., 2015; Zhang et al., 2019a,b). Therefore, six hybrid peptides were designed by combining the full-length TP5 $(19,20)$ with a characteristic fragment of LL-37 that included LL-37 (13-36) (Mookherjee et al., 2006; Molhoek et al., 2009), LL-37 (17-29) (Li et al., 2006; Tan et al., 2017), and LL-37 (13-31) (Wei et al., 2018).

TLR2 plays prominent roles in host defense and in regulating immune responses (Komai-Koma et al., 2004). TLR2 is an important signal transduction molecule that is expressed on DCs, macrophages and activated CD $4+\mathrm{T}$ cells (Komai-Koma et al., 2004). TLR2 activates the secretion of pro-inflammatory cytokines such as TNF- $\alpha$, IL- 6 , and IL- $1 \beta$ from monocytes, macrophages and dendritic cells, thereby triggering the activation of the immune response (Oliveira-Nascimento et al., 2012). Therefore, targeting TLR2 is an important therapeutic strategy against immunosuppressive diseases. Initially, the binding modes of the hybrid peptides were simply and effectively 


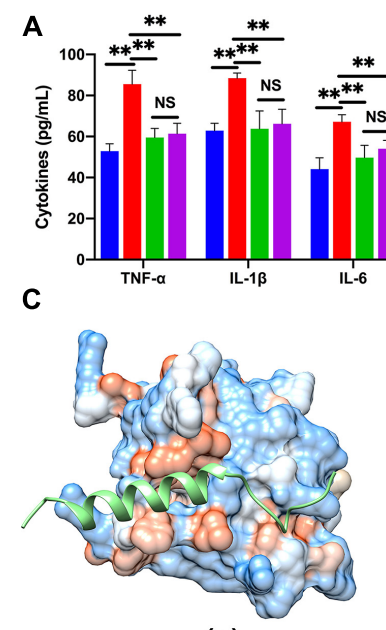

(a)
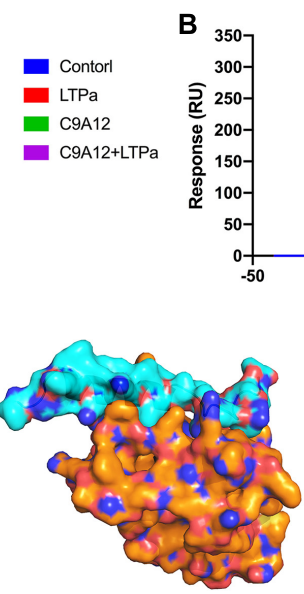

(b)
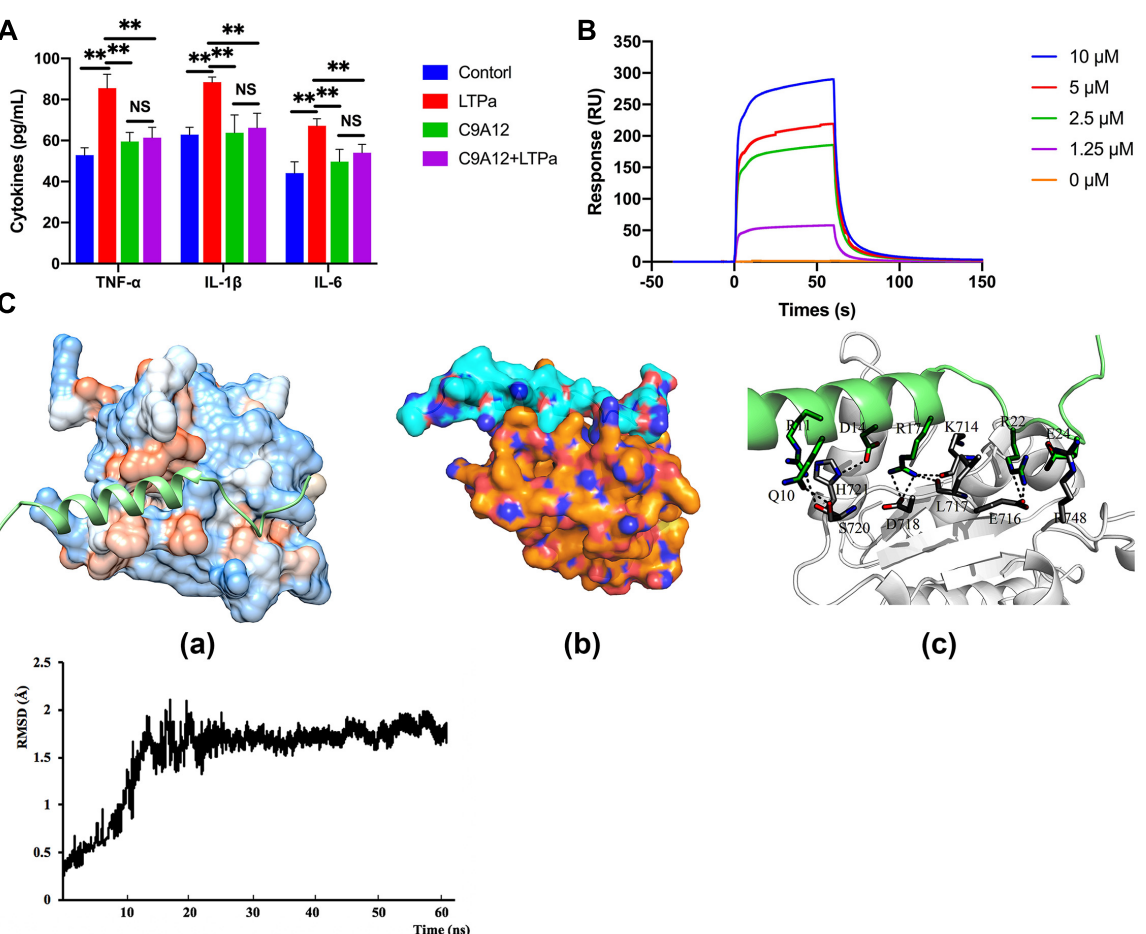

(c)

(d)

D
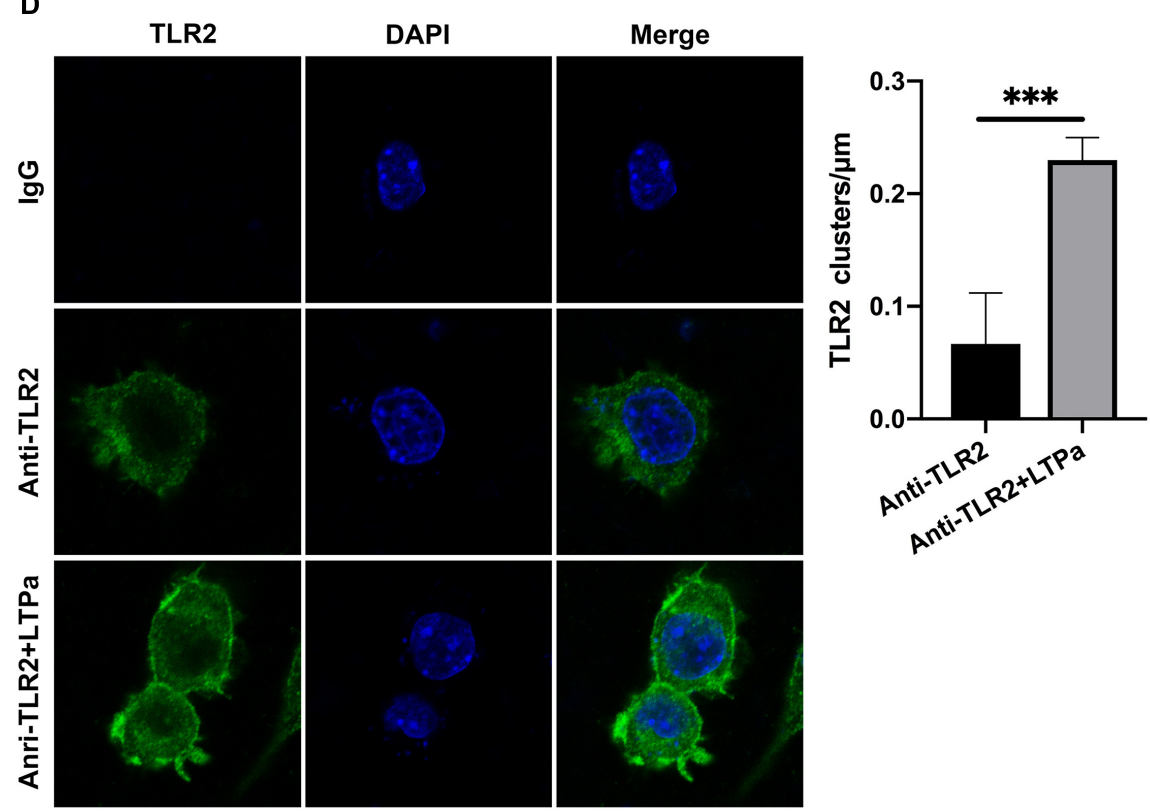

FIGURE 8 | LTPa exhibited its immunomodulatory activity by interacting with TLR2. (A) RAW264.7 cells were incubated with PBS or TLR2 mAb (C9A12) for 1 h, followed by treatment with or without $10 \mu \mathrm{g} / \mathrm{mL}$ LTPa for $24 \mathrm{~h}$. Then, the concentrations of TNF- $\alpha$, IL- 6 , and IL-1 $\beta$ in the cell culture supernatant were quantified by ELISA. (B) TLR2 was immobilized on a sensor chip, and the binding ability of LTPa was analyzed by surface plasmon resonance. (C) Docking results of LTPa on TLR2. (C-a) The whole view of TLR2 depicting the LTPa binding pocket; (C-b) electrostatic potential surface around the TLR2-LTPa complex; (C-c) closeup view of LTPa binding to TLR2. The interacting residues between LTPa and TLR2 are shown. The gray ribbons represent TLR2, and green ribbons represent LTPa. (C-d) Time evolution of RMSD during molecular dynamics simulation. (D) LTPa enhances cell surface TLR2 cluster formation. RAW264.7 cells were treated with anti-mouse monoclonal antibody TLR2 or isotype control (lgG) in the absence or presence of the indicated LTPa (10 $\mu \mathrm{g} / \mathrm{ml})$. The cells were then washed with PBS and stained with a FITC-conjugated anti-mouse IgG antibody. After washing with PBS and fixing with paraformaldehyde, the cell nuclei were stained with DAPI. The cells were then imaged with the Leica TCS SP5 confocal system. LAS AF software was used to process the images and quantify the fluorescence. In addition, to generate a fluorescence histogram profile, a line was drawn along the cell surface. Fluorescence intensities higher than 40 arbitrary units (isotype control staining) were considered clusters of TLR2 molecules. The mean values \pm standard deviation of three independent experiments were used to express the data. NS: $p>0.05$, ${ }^{* *} p \leq 0.01$, and ${ }^{* * *} p \leq 0.001$ 
TABLE 3 | Distance and salt-bridges of binding residues between LTPa and TLR2.

\begin{tabular}{|c|c|c|}
\hline Interaction Pair TLR2. . .LTPa & Distance (Å) & Number of salt-bridges \\
\hline R748...E24 & 2.50 & 2 \\
\hline E716...R22 & 2.61 & 2 \\
\hline K714...R17 & 2.98 & 0 \\
\hline L717...R17 & 3.00 & 0 \\
\hline D718...R17 & 3.12 & 2 \\
\hline H721...D14 & 3.30 & 1 \\
\hline S720...R11 & 2.89 & 0 \\
\hline S720...Q10 & 2.97 & 0 \\
\hline
\end{tabular}

screened by molecular docking. Among the six newly designed peptides, $\operatorname{LTP}_{a}$ had the most favorable docking scores for TLR2. In addition, the immunomodulatory activity of the hybrid peptides was also confirmed by in vitro experiments. The results showed that LTPa significantly increased the secretion of TNF- $\alpha$, IL-6, and IL- $1 \beta$ in comparison with the other peptides tested. Collectively, these data suggested that LTPa, the most active peptide, should be selected for further immunomodulatory experiments.

The hybrid peptide was designed to have potent immunoregulatory activity but minimal cytotoxicity. Thus, the cytotoxic activity of the hybrid peptides were evaluated by the CCK- 8 assay. The results revealed that $\operatorname{LTP}_{a}$ had lower cytotoxicity than its parental peptides.
CTX, as a typical immunosuppressant, that can interfere with the differentiation and proliferation of $\mathrm{T}$ and $\mathrm{B}$ cells. Furthermore CTX kills immune cells, and decrease cellular and humoral immune responses (Fan et al., 2013; Ren et al., 2014; Gong et al., 2015). Thus, the CTX-immunosuppressed murine model was used to evaluate the immunoregulatory effects of LTP $_{\mathrm{a}}$. The spleen and thymus play prominent roles in nonspecific immunity, so their indices are crucial features of immune function (Mei et al., 2013). As expected, there was a significant decrease in the body weight and spleen and thymus index values of the CTX-treated group compared with the control group. However, peptide treatment remarkably improved the body weight and spleen and thymus indices, and these indices in the LTPa-treated group were significantly higher than those in the LL-37-treated and TP5-treated groups.

As primary helper and effector cells in the adaptive immune response, $\mathrm{T}$ lymphocytes are important for the regulation of the immune response (Yun et al., 2018). When the immune system is suppressed, the organism is more susceptible to infection due to the decrease in the CD4 + : CD8 + ratio (Fan et al., 2018). Consistent with a previous study, CTX remarkably reduced the proportions of CD4 + and CD8 + T lymphocytes. Treatments with peptides significantly increased the proportions of CD4 + and CD8 + T lymphocytes, and the increasing level in the LTPa-treated group was significantly higher than that in the LL-37-treated group. These results suggested that LTP $_{\mathrm{a}}$ improved immune function by regulating $\mathrm{T}$ lymphocyte subsets.

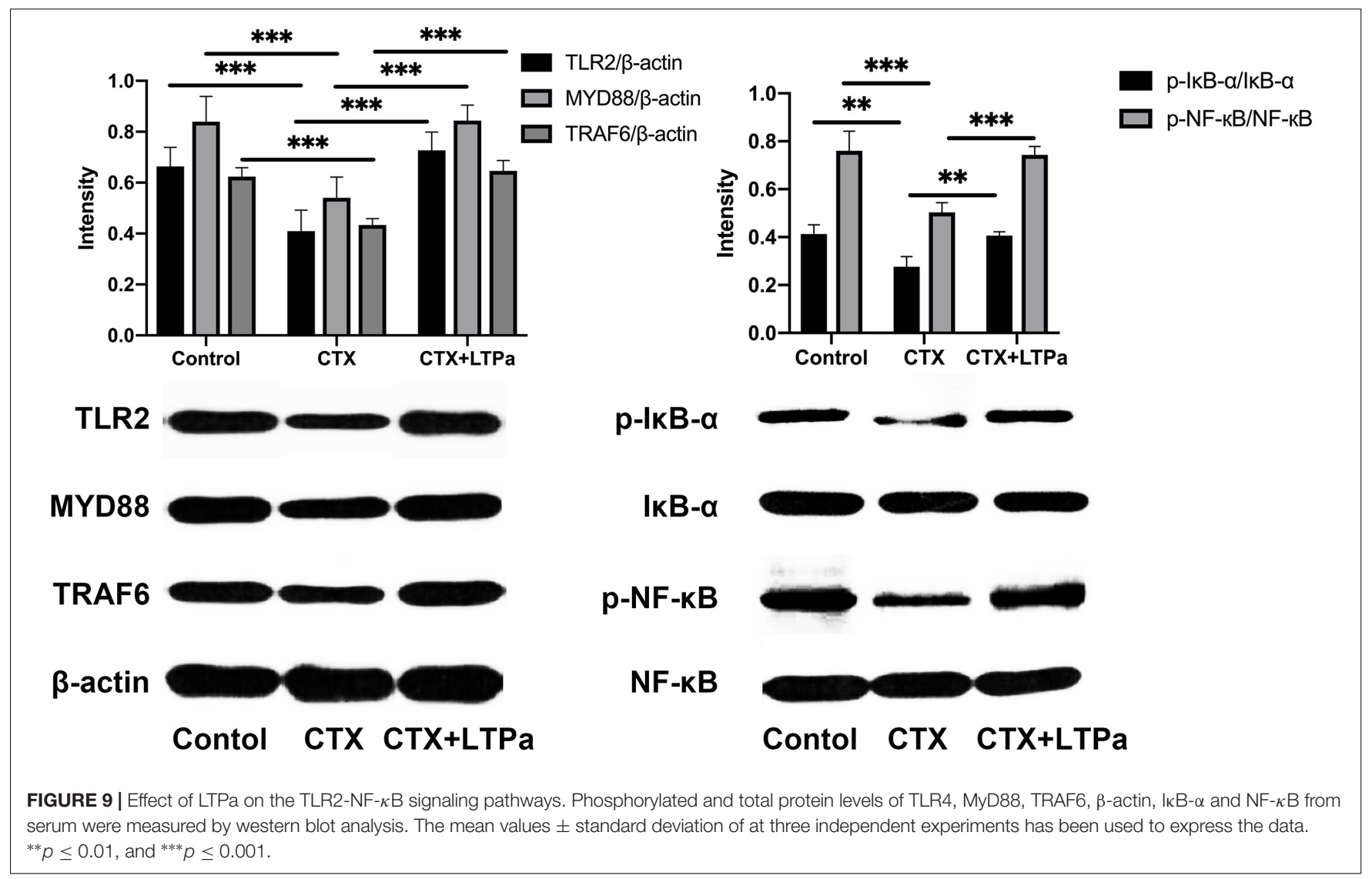


DCs are the most potent antigen-presenting cells that can regulate the activation and differentiation of $\mathrm{T}$ cells (Nace et al., 2012). It has been reported that mature DCs upregulate MHC-II, display costimulatory molecules and produce cytokines, thereby playing an important role in immune induction and regulation (Lambrecht and Hammad, 2010; Liu et al., 2015). Thus, DCs are potential targets for therapeutic intervention in immunosuppressive diseases (Liu et al., 2015). In this study, we determined the expression levels of MHC-II to investigate the effect of LTPa on serum DC maturation. The results showed that the MHC-II level was significantly decreased in the CTX-treated group but increased by LTPa treatment. In addition, the expression of MHC-II in the LTPa-treated group was significantly higher than that in the LL-37-treated and TP5-treated groups, indicating that LTPa could enhance DC maturation in CTX-induced immunosuppressed mice.

Cytokines are the key players in cell-cell communication in the immune system (Liu et al., 2016). Cytokines, such as TNF- $\alpha$, IL-6, and IL-1 $\beta$, are involved in immune regulation by coordinating hematopoietic, inflammatory, and lymphoid cells (Mei et al., 2013). The present study showed that treatment with LTPa efficiently reversed the declines in TNF- $\alpha$, IL-6, and IL-1 $\beta$ levels caused by CTX. In addition, we found that the immunomodulatory activity of LTPa was higher than that of its parental peptides.
Immunoglobulins, such as IgA, IgG, and IgM, are involved in complement activation, opsonization, and toxin neutralization (Yu et al., 2014). Levels of serum IgA, IgM, and IgG in the CTXtreated group were significantly reduced compared with those in the control group. However, pretreatment with $\mathrm{LTP}_{\mathrm{a}}$ significantly reversed the reduction. Furthermore, it is worth noting that LTPa-treated mice had significantly higher total serum IgA, IgG, and IgM levels than mice in the TP5- or LL-37-treated groups.

Collectively, these results indicate that the newly designed hybrid peptide LTPa has more potent immunoregulatory activity than its parental peptides and minimal cytotoxicity. To identify the underlying immunomodulatory mechanisms, a comprehensive and detailed analysis was conducted.

Firstly, to investigate whether the LTPa exhibited immunomodulatory properties by binding to the TLR2 as proposed, binding assays were performed by ELISA. The results showed that treatment with LTPa significantly caused increase levels of TNF- $\alpha$, IL- 6 , and IL-1 $\beta$, but pre-treatment with TLR2 mAb significantly inhibited the TNF- $\alpha$, IL-6, and IL- $1 \beta$ production induced by LTPa, indicating that LTPa exhibits its immunomodulatory effects through the TLR2 receptor. Furthermore, the binding ability of LTPa was analyzed by SPR assay, and the results confirmed that LTPa could effectively bind to the TLR2. In addition, to identify the binding sites of LTPa, we mapped the docking process of the LTPa-TLR2 complex by MD simulation. The results showed that LTPa can

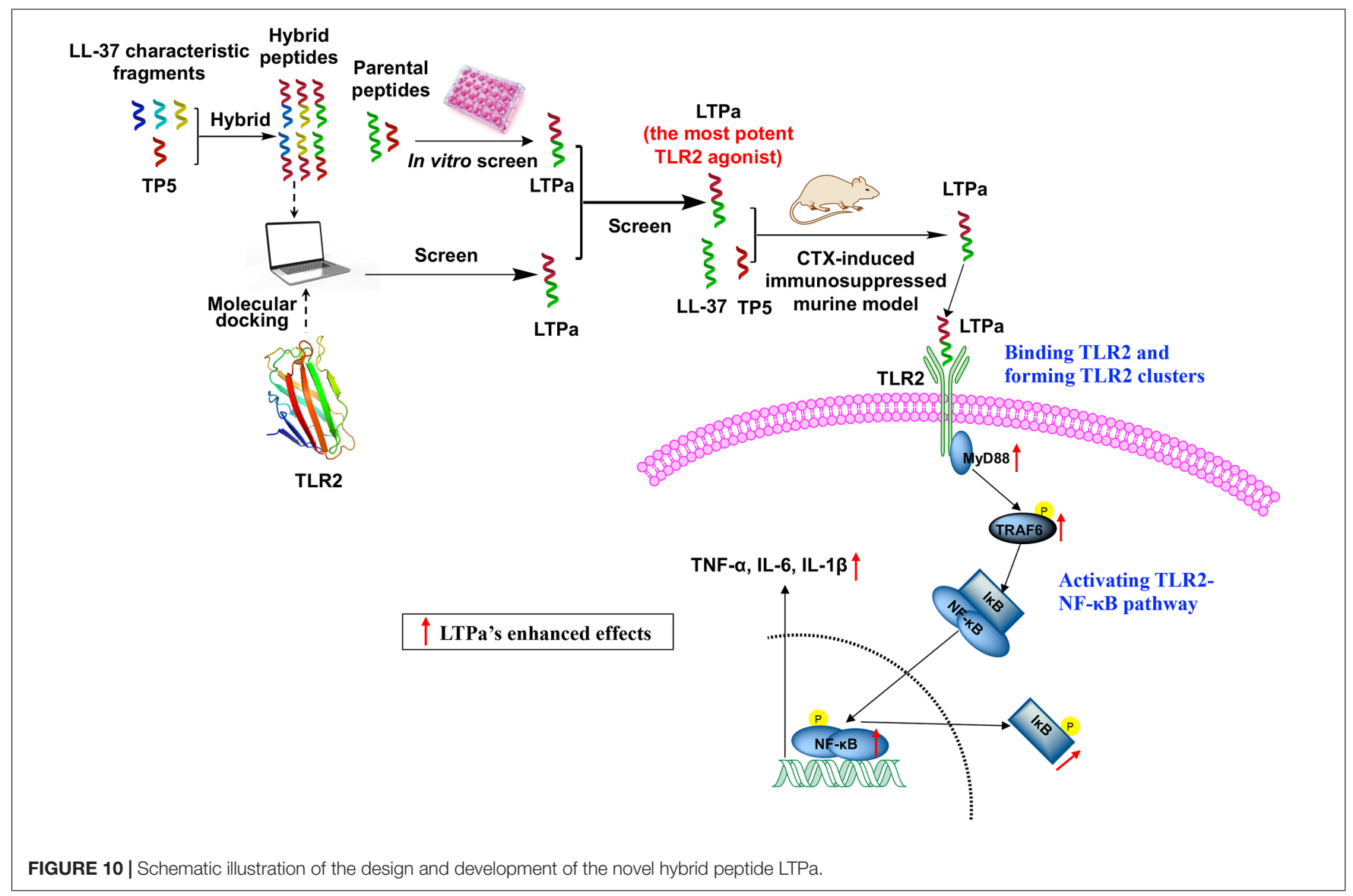


establish sustainable interaction with TLR2 by the hydrophobic interactions, which is crucial for initiating immune responses via TLRs (Seong and Matzinger, 2004). In addition, the TLR2LTPa complex is completely stable during the simulation time. Overall, these results suggested that LTPa exhibited its immunomodulatory effects depending upon binding to TLR2.

TLR2 was found to form clusters and to engage its ligand on the cell membrane where signaling was initiated (Pfeiffer et al., 2001; Triantafilou et al., 2002; Peddireddy et al., 2016). Thus, in the present study, we examined cell surface TLR2 cluster formation by confocal laser-scanning microscopy. The results showed that LTPa significantly increased the number of major TLR2 clusters per micrometer on the cell surface, which indicated that LTPa enhanced immune function by forming TLR2 clusters.

The NF- $\mathrm{B}$ signaling pathway plays a crucial role in host defenses through regulation of inflammatory gene expression (Hayden and Ghosh, 2004). MyD88 is utilized by TLR2 and recruits TRAF6, and then activates NF- $\kappa$ B signaling (Kawai and Akira, 2010). This work showed that the expression of the major proteins in the NF- $\kappa \mathrm{B}$ pathway was assessed to elucidate the immunomodulatory mechanism of LTPa. $\mathrm{LTP}_{\mathrm{a}}$ significantly increased the expression of TLR2, MyD88, and TRAF6 and the phosphorylation of I $\kappa \mathrm{B}-\alpha$ and NF- $\kappa \mathrm{B}$, indicating that $\mathrm{LTP}_{\mathrm{a}}$ could successfully activate the TLR2-NF- $\kappa \mathrm{B}$ pathway.

\section{CONCLUSION}

The successful design of $\operatorname{LTP}_{a}$ may provide a feasible approach to design novel active peptide agents with desired immunomodulatory activity and minimal cytotoxicity (Figure 10). Initially, six hybrid peptides $\left(\mathrm{LTA}_{\mathrm{a}}, \mathrm{LTA}_{\mathrm{b}}, \mathrm{LTA}_{\mathrm{c}}\right.$, TPLa, TPLb, and TPLc) were designed by combining the fulllength TP5 with a characteristic fragment of LL-37. LTPa, the most active peptide, was simply and effectively screened by molecular docking and in vitro experiments. Furthermore, the immunomodulatory effects of LTPa were confirmed by a CTXimmunosuppressed murine model, which showed that LTPa successfully inhibited immunosuppression, increased immune organ indices, enhanced DC maturation, regulated T lymphocyte subsets, and increased cytokines and Ig contents. The present

\section{REFERENCES}

Agier, J., Rozalska, S., Wiktorska, M., Zelechowska, P., Pastwinska, J., and Brzezinska-Blaszczyk, E. (2018). The RLR/NLR expression and proinflammatory activity of tissue mast cells are regulated by cathelicidin LL-37 and defensin hBD-2. Sci. Rep. 8:11750. doi: 10.1038/s41598-018-30 289-w

Akira, S., Uematsu, S., and Takeuchi, O. (2006). Pathogen recognition and innate immunity. Cell 124, 783-801. doi: 10.1016/j.cell.2006.02.015

Anders, E., Dahl, S., Svensson, D., and Nilsson, B. O. (2018). LL-37-induced human osteoblast cytotoxicity and permeability occurs independently of cellular LL-37 uptake through clathrin-mediated endocytosis. Biochem. Bioph. Res. Commun. 501, 280-285. doi: 10.1016/j.bbrc.2018.04.235

Bowdish, D. M. E., Davidson, D. J., Speert, D. P., and Hancock, R. E. W. (2004). The human cationic peptide LL-37 induces activation of the extracellular signal-regulated kinase and p38 kinase pathways in primary human monocytes. J. Immunol. 172, 3758-3765. doi: 10.4049/jimmunol.172.6.3758 study revealed that the immunomodulatory effects of LTPa are associated with binding to the TLR2, forming TLR2 clusters, and activating the NF- $\kappa \mathrm{B}$ signaling pathway.

\section{DATA AVAILABILITY STATEMENT}

The original contributions presented in the study are included in the article/Supplementary Material, further inquiries can be directed to the corresponding author/s.

\section{ETHICS STATEMENT}

The animal study was reviewed and approved by Institutional Animal Care and Use Committee of China Agricultural University.

\section{AUTHOR CONTRIBUTIONS}

LZ, XW, RZ, PM, and DS conceived the project and designed the experiments. LZ, XW, DS, BA, QC, and YT conducted experiments. LZ wrote the manuscript and analyzed data. All authors read and commented on the manuscript.

\section{FUNDING}

This work was supported by the National Key Research and Development Program of China (Project No. 2018YFD0500600), National Natural Science Foundation of China (NSFC, 31572442), and National Natural Science Foundation of China (NSFC, 31272476).

\section{SUPPLEMENTARY MATERIAL}

The Supplementary Material for this article can be found online at: https://www.frontiersin.org/articles/10.3389/fcell.2021. 620370/full\#supplementary-material

Chen, J. H., Zhang, X. G., Jiang, Y. T., Yan, L. Y., Tang, L., Yin, Y. W., et al. (2010). Bioactivity and pharmacokinetics of two human serum albumin-thymosin alpha 1-fusion proteins, rHSA-T alpha 1 and rHSA-L-T alpha 1, expressed in recombinant Pichia pastoris. Cancer Immunol. Immun. 59, 1335-1345. doi: 10.1007/s00262-010-0862-9

Duan, Y., Wu, C., Chowdhury, S., Lee, M. C., Xiong, G. M., Zhang, W., et al. (2003). A point-charge force field for molecular mechanics simulations of proteins based on condensed-phase quantum mechanical calculations. J. Comput. Chem. 24, 1999-2012. doi: 10.1002/jcc.10349

Fan, H. J., Xie, Z. P., Lu, Z. W., Tan, Z. B., Bi, Y. M., Xie, L. P., et al. (2018). Anti-inflammatory and immune response regulation of Si-Ni-San in 2,4-dinitrochlorobenzene-induced atopic dermatitis-like skin dysfunction. J. Ethnopharmacol. 222, 1-10. doi: 10.1016/j.jep.2018.04.032

Fan, Y. P., Lu, Y., Wang, D. Y., Liu, J. G., Song, X. P., Zhang, W. M., et al. (2013). Effect of epimedium polysaccharide-propolis flavone immunopotentiator on immunosuppression induced by cyclophosphamide in chickens. Cell Immunol. 281, 37-43. doi: 10.1016/j.cellimm.2013.01.008 
Goldstein, G., Scheid, M. P., Boyse, E. A., Schlesinger, D. H., and Vanwauwe, J. (1979). Synthetic pentapeptide with biological-activity characteristic of the thymic hormone thymopoietin. Science 204, 1309-1310. doi: 10.1126/science. 451537

Goldszmid, R. S., Dzutsev, A., and Trinchieri, G. (2014). Host immune response to infection and cancer: unexpected commonalities. Cell Host Microbe 15, 295-305. doi: 10.1016/j.chom.2014.02.003

Gong, Y., Wu, J., and Li, S. T. (2015). Immuno-enhancement effects of Lycium ruthenicum murr. polysaccharide on cyclophosphamideinduced immunosuppression in mice. Int. J. Clin. Exp. Med. 8, 20631-20637.

Gonser, S., Crompton, N. E. A., Folkers, G., and Weber, E. (2004). Increased radiation toxicity by enhanced apoptotic clearance of HL-60 cells in the presence of the pentapeptide thymopentin, which selectively binds to apoptotic cells. Mutat. Res. 58, 19-26. doi: 10.1016/j.mrgentox.2003.10.010

Hayden, M. S., and Ghosh, S. (2004). Signaling to NF-kappa B. Gene Dev. 18, 2195-2224. doi: 10.1101/gad.1228704

Hooper, L. V., Littman, D. R., and Macpherson, A. J. (2012). Interactions between the microbiota and the immune system. Science 336, 1268-1273. doi: 10.1126/ science. 1223490

Hu, X., Zhao, M., Wang, Y. J., Wang, Y. N., Zhao, S. R., Wu, J. H., et al. (2016). Tetrahydro-beta-carboline-3-carboxyl-thymopentin: a nano-conjugate for releasing pharmacophores to treat tumor and complications. J. Mater. Chem. B 4, 1384-1397. doi: 10.1039/c5tb01930c

Jorgensen, W. L., Chandrasekhar, J., Madura, J. D., Impey, R. W., and Klein, M. L. (1983). Comparison of simple potential functions for simulating liquid water. J. Chem. Phys. 79, 926-935. doi: 10.1063/1.445869

Kawai, T., and Akira, S. (2010). The role of pattern-recognition receptors in innate immunity: update on Toll-like receptors. Nat. Immunol. 11, 373-384. doi: $10.1038 /$ ni. 1863

Komai-Koma, M., Jones, L., Ogg, G. S., Xu, D., and Liew, F. Y. (2004). TLR2 is expressed on activated T cells as a costimulatory receptor. Proc. Natl. Acad. Sci. U.S.A. 101, 3029-3034. doi: 10.1073/pnas.0400171101

Lambrecht, B. N., and Hammad, H. (2010). The role of dendritic and epithelial cells as master regulators of allergic airway inflammation. Lancet 376, 835-843. doi: 10.1016/s0140-6736(10)61226-3

Li, J., Cheng, Y., Zhang, X., Zheng, L., Han, Z., Li, P., et al. (2013). The in vivo immunomodulatory and synergistic anti-tumor activity of thymosin alpha1thymopentin fusion peptide and its binding to TLR2. Cancer Lett. 337, 237-247. doi: 10.1016/j.canlet.2013.05.006

Li, J., Zheng, L., Li, P. L., and Wang, F. S. (2012). Intein-mediated expression, purification, and characterization of thymosin alpha 1-thymopentin fusion peptide in Escherichia coli. Protein Expr. Purif. 84, 1-8. doi: 10.1016/j.pep.2012. 04.013

Li, X., Li, Y., Han, H., Miller, D. W., and Wang, G. (2006). Solution structures of human LL-37 fragments and NMR-based identification of a minimal membrane-targeting antimicrobial and anticancer region. J. Am. Chem. Soc. 128, 5776-5785. doi: 10.1021/ja0584875

Li, Y. Q., Smith, C., Wu, H. F., Teng, P., Shi, Y., Padhee, S., et al. (2014). Short antimicrobial lipo-alpha/gamma-AA Hybrid Peptides. Chembiochemistry 15, 2275-2280. doi: 10.1002/cbic.201402264

Liu, Q., Wang, Y., Cao, M., Pan, T., Yang, Y., Mao, H., et al. (2015). Anti-allergic activity of R-phycocyanin from Porphyra haitanensis in antigen-sensitized mice and mast cells. Int. Immunopharmacol. 25, 465-473. doi: 10.1016/j.intimp.2015. 02.032

Liu, X. C., Zhu, Z. Y., Tang, Y. L., Wang, M. F., Wang, Z., Liu, A. J., et al. (2016). Structural properties of polysaccharides from cultivated fruit bodies and mycelium of cordyceps militaris. Carbohydr. Polym. 142, 63-72. doi: 10.1016/j. carbpol.2016.01.040

Liu, Y. F., Xia, X., Xu, L., and Wang, Y. Z. (2013). Design of hybrid beta-hairpin peptides with enhanced cell specificity and potent anti-inflammatory activity. Biomaterials 34, 237-250. doi: 10.1016/j.biomaterials.2012.09.032

Liu, Z. H., Zhang, J. J., Huang, X. J., Huang, L. N., Li, S. T., and Wang, Z. P. (2013). Magnesium sulfate inhibits the secretion of high mobility group box 1 from lipopolysaccharide- activated RAW264.7 macrophages in vitro. J. Surg. Res. 179, E189-E195. doi: 10.1016/j.jss.2012.02.012

London, W. B., Castel, V., Monclair, T., Ambros, P. F., Pearson, A. D. J., Cohn, S. L., et al. (2011). Clinical and biologic features predictive of survival after relapse of neuroblastoma: a report from the international neuroblastoma risk group project. J. Clin. Oncol. 29, 3286-3292. doi: 10.1200/Jco.2010.34. 3392

Ma, Z., Wei, D. D., Yan, P., Zhu, X., Shan, A. S., and Bi, Z. P. (2015). Characterization of cell selectivity, physiological stability and endotoxin neutralization capabilities of alpha-helix-based peptide amphiphiles. Biomaterials 52, 517-530. doi: 10.1016/j.biomaterials.2015.02.063

Mansour, S. C., Pena, O. M., and Hancock, R. E. W. (2014). Host defense peptides: front-line immunomodulators. Trends Immunol. 35, 443-450. doi: 10.1016/j.it. 2014.07.004

Massova, I., and Kollman, P. A. (2000). Combined molecular mechanical and continuum solvent approach (MM-PBSA/GBSA) to predict ligand binding. Perspect Drug. Discov. 18, 113-135. doi: 10.1023/A:1008763014207

Mei, Y. X., Chen, H. X., Zhang, J., Zhang, X. D., and Liang, Y. X. (2013). Protective effect of chitooligosaccharides against cyclophosphamide-induced immunosuppression in mice. Int. J. Biol. Macromol. 62, 330-335. doi: 10.1016/ j.ijbiomac.2013.09.038

Mendling, W., and Koldovsky, U. (1996). Investigations by cell-mediated immunologic tests and therapeutic trials with thymopentin in vaginal mycoses. Infect Dis. Obstet. Gynecol. 4, 225-231. doi: 10.1155/S1064744996000439

Molhoek, E. M., den Hertog, A. L., de Vries, A. M. B. C., Nazmi, K., Veerman, E. C. I., Hartgers, F. C., et al. (2009). Structure-function relationship of the human antimicrobial peptide LL-37 and LL-37 fragments in the modulation of TLR responses. Biol. Chem. 390, 295-303. doi: 10.1515/Bc.2009.037

Mookherjee, N., Brown, K. L., Bowdish, D. M. E., Doria, S., Falsafi, R., Hokamp, K., et al. (2006). Modulation of the TLR-mediated inflammatory response by the endogenous human host defense peptide LL-37. J. Immunol. 176, 2455-2464. doi: 10.4049/jimmunol.176.4.2455

Nace, G., Evankovich, J., Eid, R., and Tsung, A. (2012). Dendritic cells and damageassociated molecular patterns: endogenous danger signals linking innate and adaptive immunity. J. Innate. Immun. 4, 6-15. doi: 10.1159/000334245

Nijnik, A., and Hancock, R. E. W. (2009). The roles of cathelicidin LL-37 in immune defences and novel clinical applications. Curr. Opin. Hematol. 16, 41-47. doi: 10.1097/MOH.0b013e32831ac517

Oliveira-Nascimento, L., Massari, P., and Wetzler, L. M. (2012). The role of TLR2 in infection and immunity. Front. Immunol. 3:79. doi: 10.3389/fimmu.2012.00079

Parrinello, M., and Rahman, A. (1981). Polymorphic transitions in single crystals: a new molecular dynamics method. J. Appl. Phys. 52, 7182-7190. doi: 10.1063/ 1.328693

Peddireddy, V., Doddam, S. N., Qureshi, I. A., Yerra, P., and Ahmed, N. (2016). A putative nitroreductase from the DosR regulon of Mycobacterium tuberculosis induces pro-inflammatory cytokine expression via TLR2 signaling pathway. Sci. Rep. 6:24535. doi: 10.1038/srep24535

Pfeiffer, A., Bottcher, A., Orso, E., Kapinsky, M., Nagy, P., Bodnar, A., et al. (2001). Lipopolysaccharide and ceramide docking to CD14 provokes ligand-specific receptor clustering in rafts. Eur. J. Immunol. 31, 3153-3164. doi: 10.1002/15214141(200111)31:11<3153::aid-immu3153>3.0.co;2-0

Quayle, K., Coy, C., Standish, L., and Lu, H. L. (2015). The TLR2 agonist in polysaccharide- $\mathrm{K}$ is a structurally distinct lipid which acts synergistically with the protein-bound beta-glucan. J. Nat. Med. 69, 198-208. doi: 10.1007/s11418014-0879-z

Ren, Z., He, C. H., Fan, Y. H., Guo, L. W., Si, H. M., Wang, Y. W. et al. (2014). Immuno-enhancement effects of ethanol extract from Cyrtomium macrophyllum (Makino) Tagawa on cyclophosphamide-induced immunosuppression in BALB/c mice. J. Ethnopharmacol. 155, 769-775. doi: 10.1016/j.jep.2014.06.021

Romani, L., Oikonomou, V., Moretti, S., Iannitti, R. G., D’Adamo, M. C., Villella, V. R., et al. (2017). Thymosin alphal represents a potential potent singlemolecule-based therapy for cystic fibrosis. Nat. Med. 23, 590-600. doi: 10.1038/ nm.4305

Sastry, G. M., Adzhigirey, M., Day, T., Annabhimoju, R., and Sherman, W. (2013). Protein and ligand preparation: parameters, protocols, and influence on virtual screening enrichments. J. Comput. Aid. Mol. Des. 27, 221-234. doi: 10.1007/ s10822-013-9644-8

Scott, M. G., Davidson, D. J., Gold, M. R., Bowdish, D., and Hancock, R. E. W. (2002). The human antimicrobial peptide LL-37 is a multifunctional modulator of innate immune responses. J. Immunol. 169, 3883-3891. doi: 10.4049/ jimmunol.169.7.3883 
Seong, S. Y., and Matzinger, P. (2004). Hydrophobicity: an ancient damageassociated molecular pattern that initiates innate immune responses. Nat. Rev. Immunol. 4, 469-478. doi: 10.1038/nri1372

Singh, V. K., Biswas, S., Mathur, K. B., Haq, W., Garg, S. K., and Agarwal, S. S. (1998). Thymopentin and splenopentin as immunomodulators - current status. Immunol. Res. 17, 345-368. doi: 10.1007/Bf02786456

Su, L. J., Wang, Y., Wang, J. M., Mifune, Y., Morin, M. D., Jones, B. T., et al. (2019). Structural basis of TLR2/TLR1 activation by the synthetic agonist diprovocim. J. Med. Chem. 62, 2938-2949. doi: 10.1021/acs.jmedchem.8b0 1583

Tan, T., Wu, D., Li, W., Zheng, X., Li, W., and Shan, A. (2017). High specific selectivity and membrane-active mechanism of synthetic cationic hybrid antimicrobial peptides based on the peptide FV7. Int. J. Mol. Sci. 18:339. doi: 10.3390/ijms18020339

Tjabringa, G. S., Aarbiou, J., Ninaber, D. K., Drijfhout, J. W., Sorensen, O. E., Borregaard, N., et al. (2003). The antimicrobial peptide LL-37 activates innate immunity at the airway epithelial surface by transactivation of the epidermal growth factor receptor. J. Immunol. 171, 6690-6696. doi: 10.4049/jimmunol. 171.12.6690

Triantafilou, M., Miyake, K., Golenbock, D. T., and Triantafilou, K. (2002). Mediators of innate immune recognition of bacteria concentrate in lipid rafts and facilitate lipopolysaccharide-induced cell activation. J. Cell Sci. 115(Pt 12), 2603-2611.

Wang, J. M., Wolf, R. M., Caldwell, J. W., Kollman, P. A., and Case, D. A. (2005). Development and testing of a general amber force field (vol 25, pg 1157, 2004). J. Comput. Chem. 26:114. doi: 10.1002/jcc.20145

Wei, X. B., Wu, R. J., Zhang, L. L., Ahmad, B., Si, D. Y., and Zhang, R. J. (2018). Expression, purification, and characterization of a novel hybrid peptide with potent antibacterial activity. Molecules 23:1491. doi: 10.3390/ molecules23061491
Yu, Q., Nie, S. P., Wang, J. Q., Liu, X. Z., Yin, P. F., Huang, D. F., et al. (2014). Chemoprotective effects of Ganoderma atrum polysaccharide in cyclophosphamide-induced mice. Int. J. Biol. Macromol. 64, 395-401. doi: 10. 1016/j.ijbiomac.2013.12.029

Yun, L. Y., Wu, T., Li, Q., and Zhang, M. (2018). Dietary supplementation with purified wheat germ glycoprotein improve immunostimulatory activity in cyclophosphamide induced Balb/c mice. Int. J. Biol. Macromol. 118, 1267-1275. doi: 10.1016/j.ijbiomac.2018.06.199

Zhang, L. L., Wei, X. B., Zhang, R. J., Petitte, J., Si, D. Y., Li, Z. X., et al. (2019a). Design and development of a novel peptide for treating intestinal inflammation. Front. Immunol. 10:1841. doi: 10.3389/fimmu.2019.01841

Zhang, L. L., Wei, X. B., Zhang, R. J., Si, D. Y., Petitte, J. N., Ahmad, B., et al. (2019b). a novel peptide ameliorates LPS-induced intestinal inflammation and mucosal barrier damage via its antioxidant and antiendotoxin effects. Int. J. Mol. Sci. 20, 3974. doi: 10.3390/ijms20163974

Zhang, Y. Y., Yu, Y. Y., Zhang, Y. R., Zhang, W., and Yu, B. (2016). The modulatory effect of TLR2 on LL-37-induced human mast cells activation. Biochem. Biophys. Res. Commun. 470, 368-374. doi: 10.1016/j.bbrc.2016.01.037

Conflict of Interest: The authors declare that the research was conducted in the absence of any commercial or financial relationships that could be construed as a potential conflict of interest.

Copyright (C) 2021 Zhang, Wei, Zhang, Mozdziak, Si, Ahmad, Cheng and Tong. This is an open-access article distributed under the terms of the Creative Commons Attribution License (CC BY). The use, distribution or reproduction in other forums is permitted, provided the original author(s) and the copyright owner(s) are credited and that the original publication in this journal is cited, in accordance with accepted academic practice. No use, distribution or reproduction is permitted which does not comply with these terms. 